\title{
Attention-Deficit/Hyperactivity Disorder and Attention Networks
}

\author{
George Bush ${ }^{\star, 1,2,3,4}$ \\ ${ }^{1}$ Department of Psychiatry, Harvard Medical School, Boston, MA, USA; ${ }^{2}$ Psychiatric Neuroscience Division, Department of \\ Psychiatry, Massachusetts General Hospital, Boston, MA, USA; ${ }^{3}$ MGH/MIT/HMS Athinoula A. Martinos Center for Functional \\ and Structural Biomedical Imaging (Massachusetts Institute of Technology, Harvard Medical School and Massachusetts \\ General Hospital), Charlestown, MA, USA; ${ }^{4}$ Benson-Henry Institute for Mind-Body Medicine at Massachusetts General \\ Hospital, Boston, MA, USA
}

Research attempting to elucidate the neuropathophysiology of attention-deficit/hyperactivity disorder (ADHD) has not only shed light on the disorder itself, it has simultaneously provided new insights into the mechanisms of normal cognition and attention. This review will highlight and integrate this bidirectional flow of information. Following a brief overview of ADHD clinical phenomenology, ADHD studies will be placed into a wider historical perspective by providing illustrative examples of how major models of attention have influenced the development of neurocircuitry models of ADHD. The review will then identify major components of neural systems potentially relevant to ADHD, including attention networks, reward/feedbackbased processing systems, as well as a 'default mode' resting state network. Further, it will suggest ways in which these systems may interact and be influenced by neuromodulatory factors. Recent ADHD imaging data will be selectively provided to both illustrate the field's current level of knowledge and to show how such data can inform our understanding of normal brain functions. The review will conclude by suggesting possible avenues for future research.

Neuropsychopharmacology Reviews (2010) 35, 278-300; doi: I0.1038/npp.2009.120; published online 16 September 2009

Keywords: attention; ADHD; imaging; reward; cingulate; prefrontal

\section{INTRODUCTION}

Attention-deficit/hyperactivity disorder (ADHD) is a neuropsychiatric disorder that is characterized by developmentally inappropriate symptoms of inattention, impulsivity, and motor restlessness. With an estimated prevalence of $\sim 5$ to $8 \%$ in children, ADHD is among the most common childhood neurobehavioral disorders, and frequently persists into adolescence and adulthood (Biederman and Faraone, 2005; Faraone and Biederman, 2005; Faraone et al, 2006; Mick et al, 2004). Given the established increased morbidity associated with ADHD, including impaired academic, occupational, and social functioning, increased rates of substance abuse, traffic accidents, persistent neuropsychological impairments, and the attendant increased costs to society (Biederman, 2004; Donnelly et al, 2004; Guevara et al, 2001; Secnik et al, 2005; Vos et al,

${ }^{*}$ Correspondence: $\operatorname{Dr}$ G Bush, Psychiatric Neuroscience Program, Department of Psychiatry, Massachusetts General Hospital-East, CNY 2614, Building 149, Thirteenth Street, Charlestown, MA 02129, USA, Tel. +1 617726 8120, Fax: +1617606 3910,

E-mail: geo@nmr.mgh.harvard.edu

Received 13 April 2009; revised 28 July 2009; accepted 29 July 2009
2005), determining the underlying neural substrate of ADHD is of great import.

Convergent data from various sources, including neuroimaging, neuropsychological, genetics, and neurochemical studies, have generally implicated fronto-striatal network abnormalities as contributing to ADHD (Bush et al, 2005; Durston, 2003; Giedd et al, 2001; Kelly et al, 2007; Schneider et al, 2006; Vaidya and Stollstorff, 2008; Zametkin and Liotta, 1998). Functional imaging studies on ADHD, in particular, have increased almost exponentially over the past decade. As a crude measure, a recent functional imaging review (Bush et al, 2005) included 34 functional imaging studies, whereas a current PubMed search combining the terms 'ADHD and imaging' returned 650 results, with more than 80 papers published in the last year alone.

Given this burgeoning body of research on the neurobiology of ADHD, this review cannot be comprehensive, nor for the most part will it specifically critique individual articles. Instead, it will focus on identifying major themes within the extant ADHD literature. It will then seek to place these issues within a larger framework that shows how cognitive and affective neuroscience influences have helped shape ADHD research, and in turn how ADHD research has 
led to an improved understanding of human brain functions. This dynamic, bidirectional flow of information will be important to future progress on both fronts.

Specifically, the review begins with admittedly reductionistic introductions of the clinical phenomenology and conceptualizations of $\mathrm{ADHD}$, offered to help lay a foundation for subsequent sections on neural systems relevant to ADHD. These are followed by examples of how cognitive neuroscience models of attention have influenced the development of neurocircuitry-based models of ADHD. For example, major components of neural systems potentially relevant to $\mathrm{ADHD}$ - such as directed attention networks, a proposed 'default mode' network of the brain, and reward/motivation regions - will be identified. ADHDrelated imaging data are then selectively reviewed, highlighting emerging themes and advances. Some structural imaging studies will be mentioned, including morphometric/volumetric magnetic resonance imaging (MRI), cortical thickness analyses, and diffusion tensor imaging (DTI) of white matter connections. Functional studies include mainly positron emission tomography (PET) or functional MRI (fMRI). Neurochemical studies include magnetic resonance spectroscopy (MRS) studies. Brief mention is then made of ways in which these systems can be modulated by neurochemical influences such as dopamine. Finally, the review concludes with some suggested possible directions for future research.

\section{Clinical Features}

ADHD is a developmental syndrome whose cardinal signs are inattention, impulsivity, and hyperactivity. ADHD, per DSM-IV-TR (American Psychiatric Association, 2000), currently encompasses multiple forms of the disorder, including an inattentive form, a fairly rare purely hyperactive form, and a combined type that is the most common form and features both inattention and hyperactivity. Inattention, or the inability to direct and maintain selective attention to motivationally relevant tasks, is a key feature of the disorder. Impulsivity refers to acting rashly without apparently thinking of the consequences, such as blurting out answers in class. Hyperactivity refers specifically to excessive motor activity.

Beyond these cardinal signs, many difficult-to-quantify associated signs of ADHD exist. For example, disorganization is frequently cited as one of the main indicators of inattention. However, 'disorganization' can be produced in many different ways. Disorganization can result from poor general motivation or can reflect an impaired ability to value long-range goals over short-term rewards. Even when patients are motivated, disorganization can arise from an inability to plan ahead and order the necessary steps to accomplish the goal. Apparent disorganization could also result from poor working memory skills that impair the ability to maintain goals and/or plans in mind, or it could be produced by an inability to adjust behavior to meet changing contingencies.
To complicate matters further, in addition to diagnostic subtype heterogeneity, there is the oft-observed impression that ADHD patients can show a great deal of intraindividual variation in performance depending on the task and motivational state. ADHD patients may excel at some tasks and may even appear 'hyperfocused' if greatly interested in a task, but in other settings performance may fluctuate rapidly. Moreover, although many ADHD patients have persistent deficits on formal neuropsychological tests, many others show none (Seidman et al, 2004a). ADHD patients may be socially adept, or may display decreased frustration tolerance, increased social isolation, and affective instability.

Here especially it is crucial to always bear in mind that ADHD is a developmental disorder. This has at least two important ramifications. First, attempts to study ADHD must view ADHD in the context of what is developmentally appropriate and account for age-related changes in the neurobiology of patients at different ages. Stated another way, the neural structures and functional capacity of children, adolescents, and adults vary in both healthy humans and those with ADHD, which complicates intergenerational comparisons. Second, genetically mediated neuronal deficits can lead to secondary functional/psychological impairments that may not necessarily arise directly from primary neural insults. For example, inattention can make it difficult for a child to learn the basic educational skills that lay the foundation for good school performance, which can lead to subsequent anxiety, depression, poor selfesteem, and acting out for attention in a dysfunctional spiral. These affective and behavioral sequelae may have their own effects on neural structures and function that will need to be disentangled from any primary insult. Finally, it should be noted that although diagnostic schemes focus on impairments associated with ADHD, there are arguably likely to be positive aspects of having ADHD - such as increased creativity, novel problem-solving abilities, and possibly greater passion for tasks that interest people with $\mathrm{ADHD}$ - that have led to ADHD's persistence over time in humans. Thus, it is difficult to identify which of these processes may be 'core features' of ADHD, and which may emerge as secondary sequelae or comorbidities. However, major points that can be gleaned from this brief clinical overview are (1) that ADHD is diagnostically, developmentally, and neuropsychologically heterogeneous; (2) despite this clinical complexity, it is possible to identify different cognitive, motor, and emotional processes that might, if altered, contribute to ADHD symptomatology; and (3) that testable neural circuitry models can be constructed from these observed clinical features.

Disentangling these issues has important ramifications not only for ADHD but also, in turn, for understanding normal cognition, emotion, and motivation. Myriad dysfunctional processes could potentially contribute to ADHD. These could include abnormalities of neural responses underlying anticipation or planning of actions, target selection, filtering of distracting information, working 
memory, response selection and/or inhibition, novelty detection, error signaling, reward evaluation, and feedback-mediated decision-making processes. Thus, research must first identify the neural circuitry that underlies these processes in healthy humans, and then subsequently test the integrity of these pathways in patients with ADHD.

For example, inattention can be produced in a number of ways that can be amenable to testing through functional and structural neuroimaging. Attention dysfunction might result from impaired target selection processes. Alternatively, inadequate filtering ability might allow excessive amounts of distracting information to interfere with the processing of relevant stimuli. Patients with ADHD might be able to select relevant information normally, but motivational deficits or working memory problems might preclude them from being able to maintain focus for long enough periods of time to act on the information. It is possible that central evaluative dysfunction could interfere with the normal ability to link rewards or errors with actions. Such an inability to translate motivational information into appropriate behaviors is likely to be an important part of ADHD, and could explain the observation that patients with ADHD can perform well on interesting tasks, but show inabilities to perform on tasks that are deemed boring or irrelevant. Similarly, impulsivity and/or hyperactivity could be produced by impairments of brain regions that have roles in inhibiting undesired or inappropriate motor behaviors.

In return, each study of ADHD - when viewed as a type of 'natural lesion study' - provides a window on normal cognitive, emotional, motor, and/or motivational brain processes. As dysfunction of many different interacting brain regions could have roles in the pathophysiology of ADHD, studies on ADHD have great relevance to cognitive and affective neuroscience. In these ways, studies on ADHD provide important bidirectional flows of information about multiple brain regions that clarify our understanding of neural function in both clinical and healthy populations.

\section{Conceptualizations of ADHD}

Over the past century, the conceptualizations of ADHD have varied, as have the hypothesized explanations for the inattention and disruptive behaviors associated with it. Early accounts of an ADHD-like syndrome (Still, 1902) focused on volitional impairments, attributing the disorder to impaired abilities to inhibit voluntary acts and defects of moral regulation. As reviewed elsewhere (Barkley, 1990; Werry, 1992), based in large part on non-rigorous scientific methods, an ADHD-like syndrome was for a time viewed non-specifically as minimal brain damage. Later, emphasis was placed on the primacy of hyperactivity (Chess, 1960; Denhoff et al, 1957; Laufer and Denhoff, 1957). The work by Douglas (1988)through the 1970s and 1980s then argued for a greater recognition of the role poor-sustained attention and impulse control played, along with reports of preferences for immediate reinforcers, and eventually concluded that the core deficiencies were linked to central impairments of self-regulation.

A number of cognitive psychology-based causal models have been offered to account for the clinical presentation of ADHD. A landmark paper that helped to transition toward more modern conceptualizations of ADHD by Barkley (1997) posited that the core problem in ADHD lay in dysfunctional behavioral inhibition. The theoretical model linked this dysfunction to impairments of four executive neuropsychological functions, namely working memory, regulation of affect-motivation-arousal, internalized speech, and reconstitution (higher level analysis of behavior). Importantly, although some argue with the conclusion that the inattention of ADHD should be viewed not as a primary symptom, but rather as a secondary manifestation of poor behavioral inhibition and cognitive interference control, this paper also helped drive the field forward by helping to establish testable hypotheses and to integrate the similar conceptualizations of prefrontal cortical functions advocated by Bronowski (1977) and Fuster (1989) into his framework.

Quay (1988) viewed the main problem as an imbalance between behavioral activating and inhibiting systems, arguing that ADHD was caused by underactivity of the behavioral inhibition system. Others (Schachar et al, 2000) have discussed how impulsivity and/or hyperactivity could be produced by impaired inhibition of undesired or inappropriate motor behaviors. Sergeant $(2000,2005)$ have proposed a cognitive-energetic model that details how the dysfunctional interplay of top-down and bottom-up processes at three levels (computational mechanisms of attention, state factors, and executive functions) could impair the overall efficiency of information processing in ADHD.

Sonuga-Barke and colleagues have pointed out a number of challenges for the exclusive executive function system abnormality frameworks of ADHD, such as that proposed by Barkley, and have instead advocated a dual-pathway conceptualization (Sonuga-Barke, 2003; Sonuga-Barke and Sergeant, 2005; Sonuga-Barke et al, 2008). This dualpathway account combines meso-cortically mediated executive function deficit concepts with a motivation-based account that implicates dysfunction of reward circuitry. Specifically, impaired delay aversion in some ADHD patients, presumably caused by defects in the meso-limbic modulation of reward-sensitive areas such as the ventral striatum and nucleus accumbens, leads ADHD patients to attempt to escape or avoid delay. Although Sagvolden et al's (2005) dynamic developmental behavioral theory similarly emphasizes the role of delay aversion in its explanation of the hyperactive and combined types of ADHD, SonugaBarke's more broad-based model views his proposed dual pathways as complimentary, rather than competing, accounts of multiple subtypes of ADHD (inattentive, hyperactive, and combined). Nigg and Casey's (2005) view of combined-type ADHD extends this type of neuronal modeling by additionally drawing in frontocerebellar 
dysfunction to explain timing deficits and frontoamygdalar abnormalities as the substrate of affective problems. The above papers and reviews have discussed some of implications for the various frameworks on our understanding of the pathophysiology of ADHD (Castellanos et al, 2008; Coghill et al, 2005; Sonuga-Barke et al, 2008; Swanson et al, 1998; Tannock, 1998). Overall, although parsimonious models are preferred if appropriate, in the case of ADHD it is most likely that broader, more inclusive models akin to those offered by Sonuga-Barke (2005) and Nigg and Casey (2005) will offer a better explanation of the complex and heterogeneous clinical presentations of ADHD subtypes.

\section{Cognitive Neuroscience Influences Relevant to ADHD Research}

The field of cognitive neuroscience - with its search for the neurobiological substrates of component brain processes of cognition, attention, working memory, and motor control-has had an enormous effect on the current conceptualizations of ADHD. Although a detailed review comparing and contrasting different cognitive models, such as offered elsewhere (Posner, 2004), is beyond the scope of this paper, a few major influences on ADHD research can be identified.

One of the earliest and most influential cognition-related theories that attempted to explain selective attention was 'selection for action' (Allport, 1980, 1987; Posner and Petersen, 1990). This model sought to connect the modulation of attention and target identification with response selection. Specifically, it posited that attention would be selectively focused on target stimuli that were relevant to a response selection. Selection for action did not, however, require that an actual motor response be made, but could refer to an internally represented decision. Norman and Shallice (1986) referred to this form of attention as 'supervisory,' and suggested that it was used whenever processing of non-routine information was required. Furthermore, this form of attention was distinct from simple sensory orienting, and seemed to reflect a high level of cognitive control (Posner and Rothbart, 1998).

The review paper by Posner and Petersen (1990) on the attention system of the brain has been particularly influential. This model proposed that the 'attention system' was composed of three anatomically distinct but interacting network subsystems that influenced lower information processing modules. The three subsystems were those of orienting, detecting, and alerting/vigilance. Orienting referred to sensory processes such as visual foveation of a stimulus, and was proposed to rely on the parietal cortex, superior colliculus, and pulvinar/thalamus. The detection subsystem or 'anterior attention system' consisted of the anterior cingulate cortex (ACC) and lateral prefrontal cortex, and was posited to be responsible for detecting targets that would undergo further information processing. The alerting system, encompassing the noradrenergic locus coeruleus influences on mainly right hemisphere structures, was responsible for maintaining general vigilance. Early PET studies on attention and vigilance by Pardo et al (1990) supported the framework of Posner and Petersen (1990) : performance of a Stroop selective attention task-activated ACC, whereas a vigilance task-activated right lateral prefrontal and parietal cortex did not activate the ACC (Pardo et al, 1991). On the basis of, in part, this framework, Corbetta et al (1991) concluded that the ACC modulated the lower visual area activity during a divided attention task, and Raichle et al (1994) implicated the ACC as supporting novelty processing. Later, Corbetta (1998) and Corbetta et al (1998) expanded examination of these systems, identifying roles for frontal and parietal regions in attention. Together, these studies attempted to outline neurally plausible mechanisms for attention that stressed that regulation of subservient brain areas might depend on the degree of cingulo-fronto-parietal (CFP) activation. More recent functional imaging evidence has also supported Posner and Petersen's three-module framework and started to link these brain findings to genetic influences (Fan et al, 2003, 2005; Fan and Posner, 2004). Certainly, the selection-foraction influence (Holroyd, 2004), directly or indirectly, was evident in many subsequent papers involving a large variety of motor response selection tasks relevant to ADHD, including modality-specific motor choice (Paus et al, 1993), motor control/monitoring, and/or willed action (Badgaiyan and Posner, 1998; Liddle et al, 2001; Luu et al, 2000; Picard and Strick, 2001; Turken and Swick, 1999), Stroop and Stroop-like tasks (Bush et al, 1998; Pardo et al, 1990), and tasks involving the over-riding or inhibition of prepotent responses such as go/no-go, stop-signal, or countermanding tasks (Alderson et al, 2007; Aron et al, 2003; Durston et al, 2003a; Ito et al, 2003; Kawashima et al, 1996). Although lacking in the full, necessary precision desired for a complete mechanistic account of attention, selection for action helped pave the way for studies trying to link brain processes with attention and ADHD.

\section{CFP Attention Network}

On the basis of these studies and the wider cognitive neuroscience literature, imaging studies attempting to identify the pathophysiology of ADHD logically searched for abnormalities of brain regions that are normally involved in attention, cognition, executive function, motor control, response inhibition, working memory, and/or reward/motivation. As detailed below, this line of thinking led researchers to gravitate toward studies on the dorsal anterior midcingulate cortex (daMCC), dorsolateral prefrontal cortex (DLPFC), ventrolateral prefrontal cortex (VLPFC), and parietal cortex. Although the cingulate cortex nomenclature has been revised as the field has matured, it is noted here that the term 'daMCC' refers to essentially the same region of the cingulate cortex that was referred to previously as the ACC or as the dorsal ACC in many contemporary references (Bush, 2009; Vogt, 2005; Vogt et al, 1992). Together, these regions comprise the main 

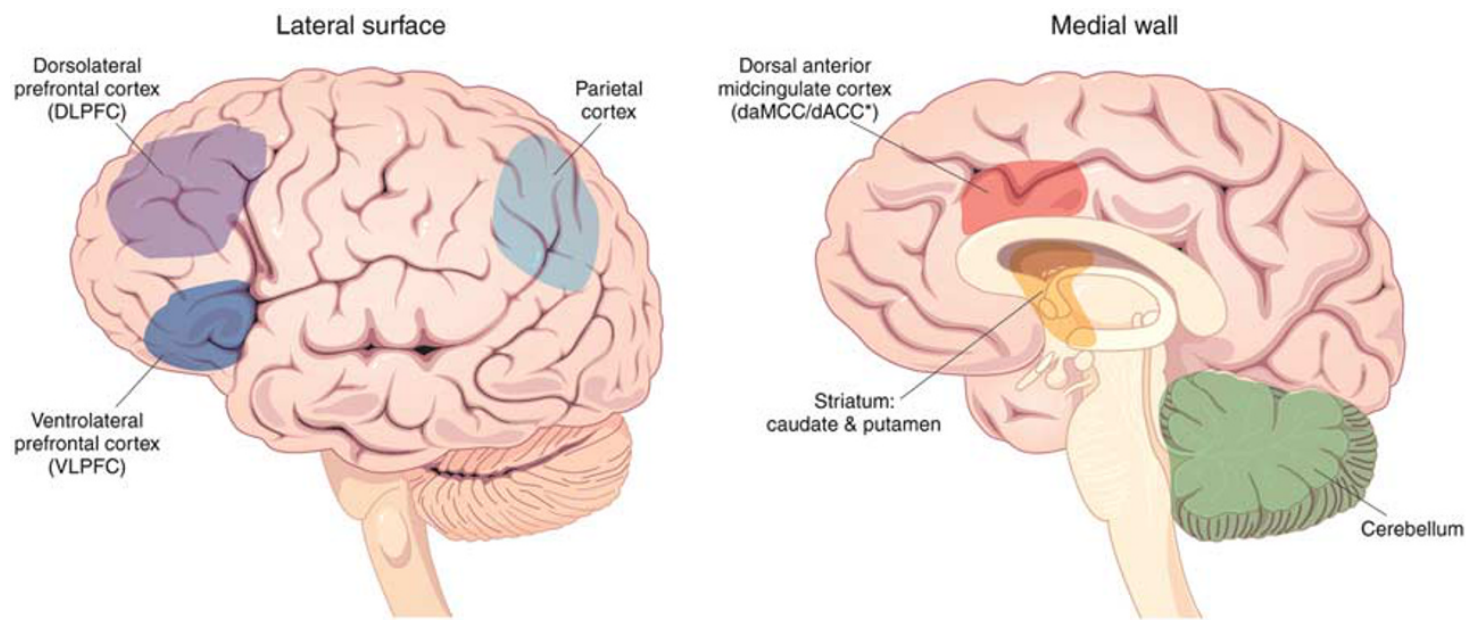

Figure 1. Brain structures implicated in ADHD. Interacting neural regions have been implicated in ADHD. In particular, the dorsal anterior midcingulate cortex (daMCC), dorsolateral prefrontal cortex (DLPFC), ventrolateral prefrontal cortex (VLPFC), parietal cortex, striatum, and cerebellum-all key elements of cognitive/attention networks - have also been found to display functional abnormalities in multiple studies of ADHD.

components of the CFP cognitive-attention network. These areas, along with the striatum, premotor areas, thalamus, and possibly cerebellum, have been identified as nodes within parallel networks of attention and cognition (Alexander et al, 1986; Berman and Colby, 2008; Cabeza and Nyberg, 2000; Colby, 1991; Colby and Goldberg, 1999; Duncan and Owen, 2000; Goldman-Rakic, 1988; Mesulam, 1981, 1990, 1999; Morecraft et al, 1993; Posner and Petersen, 1990; Posner and Rothbart, 1998) (Figure 1).

The above heuristic characterization is admittedly an over-simplified framework that is presented insofar, as it can be useful in helping to integrate new information. Many of the brain 'regions' listed above encompass multiple functional subdivisions and participate in several different information processing calculations. Clearly, a single abnormality of any one region alone does not cause ADHD. The following will provide some representative examples of the logic that drove some ADHD studies to specifically focus on some of these areas. For example, although the CFP network has been central to many studies, a number of studies have focused on the striatum, which not only participates in attention functions but also has crucial roles in motivation/reward processing. This will be followed by the offering of a few examples of complicating factors that preclude straightforward linking of imaging results with defined pathophysiological processes. After this basic foundation is laid, some representative examples of recent advances in ADHD imaging will be highlighted.

Prefrontal cortex. One of the main findings from a pioneering ADHD PET imaging study by Zametkin et al (1990) was that of global underactivity, with global cerebral glucose metabolism reported as $8.1 \%$ lower in ADHD patients than in healthy controls. This study also found that the ADHD group showed regional hypoactivity of attention and motor control areas including the daMCC, superior prefrontal cortex, and premotor cortex. Most ADHD imaging studies have sought to identify localized brain dysfunction, and the prefrontal cortex was one of the first areas to be studied, because of similarities between patients with ADHD and those with frontal lobe injuries (Barkley, 1997; Barkley et al, 1992; Mattes, 1980). Structural imaging studies on ADHD have identified both significantly smaller global cerebral volumes of $\sim 3$ to $4 \%$ in ADHD, as well as specifically smaller prefrontal volumes in ADHD (Seidman et al, 2004b; Valera et al, 2007). Some functional investigations extended beyond the frontal lobes, hypothesizing insufficient frontal cortical inhibitory control (Casey et al, 1997a, b; Satterfield and Dawson, 1971); a view that drew support from studies on stimulant medications and animal models that have implicated dopaminergic and noradrenergic influences on the prefrontal cortex (Arnsten and Dudley, 2005; Brennan and Arnsten, 2008; Shaywitz et al, 1978). Over time, better characterization by cognitive neuroscience of the specific roles that the prefrontal cortex plays within distributed networks of brain regions underlying attention, cognition, and behavioral self-regulation (Cabeza and Nyberg, 2000; Fuster, 1989; Goldman-Rakic, 1988; Posner, 2004; Posner and Petersen, 1990) has led to refined searches for dysfunction in various subdivisions of the prefrontal cortex (Bush et al, 2005; Denckla, 1989; Sergeant et al, 2002). Specifically, researchers began by focusing on the DLPFC and VLPFC, as these regions are believed to support vigilance, selective and divided attention, attention shifting, planning, executive control, and working memory functions (Duncan and Owen, 2000; Posner and Petersen, 1990). Also, the VLPFC in particular has been associated with behavioral inhibition, as evidenced by its activation using stop-signal tasks (Aron et al, 2003; Rubia et al, 1999). Together, these findings have made the prefrontal cortex a prime candidate for study by ADHD researchers. 
It can be noted that, although the orbitofrontal cortex (OFC) is crucially important to reward processing and motivation, and OFC lesions have been associated with social disinhibition and impulse control problems (Hesslinger et al, 2002), OFC has unfortunately remained a relatively understudied prefrontal region. This is likely because of, in part, the generally wider interest in DLPFC functioning, and possibly in part because of the fact that fMRI of OFC is complicated by the well-known high frequency of susceptibility artifacts in this region. OFC thus represents an opportunity area for bidirectional influence, as the need to better understand reward circuitry contributions to ADHD should spur interest in developing refined fMRI methods to image areas such as OFC that are prone to susceptibility artifacts. The use of such methods will help identify potentially dysfunctional reward circuitry in ADHD.

daMCC: cognition/attention and reward. The daMCC, located on the medial surface of the frontal lobe, refers to areas $24 c^{\prime} / 32^{\prime}$ in humans. The nomenclature of cingulate subdivisions has evolved over the past few decades (Bush, 2009; Bush et al, 2008; Vogt, 2005): for simplicity here, the daMCC is equivalent to the dorsal ACC (Bush and Shin, 2006; Bush et al, 2002) and broadly consistent with the older term, the ACC, used by studies above (Alexander et al, 1986; Posner and Petersen, 1990). The daMCC maintains strong reciprocal connections with other cognitive/attention and motor regions, including the DLPFC, parietal cortex, premotor cortex, and striatum. Although much attention has been paid to the lateral prefrontal cortex, the most consistent cross-study and cross-modality data identifying a region as dysfunctional in ADHD have been provided for the daMCC (Bush, 2009). The daMCC has critical roles in attention, cognitive processing, target detection, novelty detection, response selection, response inhibition, error detection, and motivation.

Particularly relevant to reward/motivation and cognitive theories of ADHD, the daMCC is a key modulator of moment-to-moment adjustments in behavior through its primary role in feedback-based decision-making. As detailed elsewhere (Bush, 2009; Bush et al, 2002; Williams et al, 2004), this feedback-based decision-making conceptualization of the daMCC is based on compelling evidence from single-unit studies in monkeys and humans, as well as on human neuroimaging studies. In essence, it states that the daMCC encompasses a local intracortical network comprised of functionally heterogeneous cells. These cells variously anticipate and signal motivationally relevant targets, indicate novelty, encode reward values, signal errors, and influence motor responses. The daMCC's roles in attention and cognition are to integrate goal and feedback-related information from various sources and then to use this information to modulate activity in executive brain regions that direct attention and produce motor responses. The daMCC thus acts within cognitive- reward-motor networks to increase the efficiency of decision-making and execution.

Again, the daMCC is but one component of reward circuits that include the striatum, nucleus accumbens, and OFC (Galvan et al, 2005; Haber and Brucker, 2009; Schultz et al, 2000; Ullsperger and von Cramon, 2003); just as it is a component of CFP cognitive-attention networks. Given this, daMCC dysfunction could directly and/or indirectly lead to all of the cardinal signs of ADHD (inattention, impulsivity, and hyperactivity), and could explain the observation that ADHD subjects can perform well when motivated on some tasks, but may perform poorly when the task is not interesting. As will be discussed below, numerous functional, structural, neurochemical, and pharmacological imaging studies have identified abnormalities of the daMCC in ADHD.

Parietal cortex. The parietal cortex has key roles in attention allocation and encompasses polymodal sensory convergence areas (Corbetta, 1998; Corbetta et al, 2000; Culham, 2002; Culham and Kanwisher, 2001). Although the parietal cortex has been the a priori focus of relatively few ADHD functional imaging studies, it has been identified as displaying altered function in ADHD. Although this may reflect abnormal input from regions connected to the parietal cortex, some structural (cortical thickness) abnormalities in the parietal cortices of those with ADHD would suggest that the functional abnormalities do have a role in ADHD pathophysiology.

Striatum. Similar to the cingulate and lateral prefrontal cortex, the striatum also has multiple roles relevant to ADHD. The striatum contains key components of separable, parallel-distributed circuits that support executive and motor functions (Alexander et al, 1986), reward processing, and decision-making (Haber, 2003; Schultz, 2006). Haber's spiraling circuits model (2003) — which discusses how PDP subsystems can have separate but interacting properties - has particular relevance to $\mathrm{ADHD}$, as it was used as a framework that illustrates dissociable striatal contributions to ADHD. Specifically, Castellanos et al (2006) postulate that executive function deficits will be linked with the anterior striatum, DLPFC and daMCC dysfunction, whereas delay aversion symptoms will be tied to dysfunction of motivational/reward areas including the ventral striatum and orbitomedial prefrontal cortex. Pursuit of the answers to these questions represents a true opportunity for bidirectional influences in research, for if these predictions are borne out, then they will not only help determine ADHD pathophysiology but will also shed light on striatal contributions to normal executive functions and reward processing.

As reviewed elsewhere, morphometric MRI studies have frequently reported caudate volumetric abnormalities (Giedd et al, 2001; Seidman et al, 2005; Valera et al, 2007). Over the past decade, numerous studies have focused on the role dopamine may play in both the pathophysiology 
of ADHD and the mechanisms of action of medications used to treat ADHD. Owing to technical characteristics of the techniques used to study dopamine, much of this literature has been limited to te striatum. Also, a number of functional imaging studies have identified striatal abnormalities in ADHD. Coupled with the structural and dopaminergic data, and the growing understanding of striatum's role in reward/motivation, these collected fMRI study results will continue to make the striatum a prime target of future imaging studies.

Other regions. Other brain regions, including the cerebellum, superior temporal sulcus, thalamus, and the brain stem reticular activating system, have not been the main focus of many functional imaging studies on ADHD to this point, but this is slowly changing. Reasons vary for the relative neglect of these areas. Regarding the cerebellum, it has only more recently been recognized as contributing to cognitive functions beyond its role in modifying motor output, thus there have been fewer tasks devoted to determining whether and how it is associated with ADHD. The thalamus and the brain stem reticular activating system, which help modulate attention and filter interfering stimuli (Vogt and Gabriel, 1993), can be difficult to image because of susceptibility artifacts and greater pulsatile motion. Future studies will be improved by refined understanding of the specific functions of these brain regions and by continued improvements in imaging techniques that will permit better testing of these regions.

\section{Parallel Distributed Processing}

Another example of bidirectional influences is the intertwined cognitive science neural modeling and computer modeling that has occurred in the past half-century. Cognitive neuroscientists were proposing models of cognition and brain functions that emphasized the parallel-distributed processing (PDP) nature of component neurons. These concepts were directly and indirectly drawn from computer neural PDP network models that themselves were inspired by attempts to model biological neural systems (McClelland et al, 1986; Rumelhart et al, 1986).

Seminal cognitive neuroscience work in this area was contributed by Alexander et al (1986), who offered a segregated, basal ganglia-thalamocortical circuitry model supporting functions including motor and oculomotor control, spatial memory, and limbic functions, and by Goldman-Rakic (1988), who laid out PDP model of brain regions supporting cognition. Others have provided PDP models that variously focused on attention (Mesulam, 1990, 1999), orienting and eye movements (Corbetta et al, 2002, 2008), parsing of top-down control and reorienting attention subsystems (Fox et al, 2006), spatial attention (Colby, 1991; Mesulam, 1981), spatial-motor systems (Colby and Goldberg, 1999), memory (Mesulam, 1990), and computer simulations of attention and effortful processing (Dehaene et al, 1998).
A recent paper that used sophisticated event-related fMRI and functional connectivity analyses to parse different elements of proposed interacting PDP subnetworks of attention responsible for expectancy, shifting attention, and reorienting (Shulman et al, 2009). Specifically, separable attention subnetworks were found to support the maintenance of attention on a target, cued shifts of attention, and reorienting to an unexpected target. Study designs such as this one, or the Attention Network Test (Fan et al, 2002), which was designed to identify separate alerting, orienting, and executive attention subnetworks, may help identify specific attention subsystem abnormalities in ADHD. Together with the earlier study of Posner and Petersen (1990), these PDP network papers have combined to identify many of the networked brain regions that have now been implicated in normal attention and motor control, as well as in the pathophysiology of ADHD, such as the daMCC, DLPFC, VLPFC, right temporoparietal junction, striatum, and parietal cortex.

\section{Resting/Default State and Cognition-Emotion- Vigilance Interactions}

Recently, studies on 'resting brain' activity have provided complementary information to data produced using cognitive activation paradigms. As will be shown, ADHD theorists have begun to hypothesize and examine how abnormalities of brain systems that normally subserve the resting state and vigilance functions may intrude upon and disrupt attention systems in ADHD (Sonuga-Barke and Castellanos, 2007; Weissman et al, 2006). To appreciate how these systems may affect one another requires a brief introduction on cognitive-emotional-vigilance system interactions and recent imaging work on the resting state of the brain.

Cognitive, emotional, and vigilance processes dynamically interact with one another to produce the full range of perceptions, thoughts, feelings, and behaviors observed in humans. For example, external sensory deprivation increases attention to endogenous stimuli (Solomon et al, 1961), as does increasing the predictability of external events (Antrobus et al, 1966; Pope and Singer, 1976). Conversely, difficult cognitive tasks decrease attention to endogenous stimuli (Antrobus et al, 1966; Pope and Singer, 1976; Teasdale et al, 1995). A number of studies have now focused on the complex interactions of personality, emotion, cognition, reward, and decision-making (Allman et al, 2001; Bechara et al, 2000; Bush et al, 2000, 2002; Damasio, 2001; Davidson, 2001; Devinsky et al, 1995; Gehring and Fencsik, 2001; Gray et al, 2002; Mayberg et al, 1999; Posner and Raichle, 1998; Simpson et al, 2001b; Vogt et al, 1992; Whalen et al, 1998). Full characterization of these complex relationships will be essential to understanding the pathophysiology of ADHD, but at present there are many unresolved issues.

Functional neuroimaging ( $\mathrm{fMRI}$ and PET) have provided clues as to how these interactions may occur. Although 
most imaging studies have concentrated on activations, or increases in regional cerebral blood flow (rCBF) or fMRI signal during the task of interest as compared with a control task, a few have focused on 'deactivations,' or decreases in rCBF or fMRI signal during the task of interest relative to a control task (Bush et al, 2000; Drevets and Raichle, 1998; Gusnard et al, 2001; Gusnard and Raichle, 2001; Mayberg et al, 1999; Raichle et al, 2001; Shulman et al, 1997; Simpson et al, 2001a, b, 2000; Whalen et al, 1998).

Raichle and colleagues (Gusnard and Raichle, 2001; Raichle et al, 2001; Simpson et al, 2001b) have argued that such decreases provide evidence of a 'default mode' or homeostatic brain state maintained during rest or visual fixation. Paraphrasing Gusnard and Raichle (2001), three separable 'networks' of brain regions support: (1) cognition, or focused, goal-directed behavior; (2) internal state monitoring, involving the regulation of emotions, motivational state and endogenous stimuli; and (3) vigilance for salient external stimuli. Summarizing data from many studies, they noted that compared with a fixation/rest 'default state,' cognitive tasks activate brain regions such as the daMCC, DLPFC, and posterior parietal cortex. Conversely, cognitive tasks deactivate the perigenual ACC, medial PFC, portions of the VLPFC, amygdala, posteromedial areas such as the posterior cingulate cortex (PCC), retrosplenial cortex, and precuneus, and other posterolateral parietal areas near the angular gyrus. This led them to suggest that these latter areas are 'tonically active' during unstructured rest periods to support vigilance of the environment and monitoring of the internal milieu. Suspending activity in brain regions supporting emotion and/or vigilance - such as the perigenual ACC, amygdala, and PCC (Davis and Whalen, 2001; Hayden et al, 2009; Rauch et al, 2006; Wager et al, 2008; Whalen et al, 1998) - could improve cognitive task performance by reducing interference from sources unrelated to the task at hand, much as in the same way that during selective attention tasks, gating information from unattended channels improves processing of attended stimuli. However, as these vigilance and internal state regions could help protect against predators and signal important changes in the internal state and/or motivation, they should only be suppressed when necessary, such as when interfering with cognitive task performance. In line with these fMRI and PET results, intracranial single-unit recording work has shown decreased single-neuron activity in the perigenual ACC during a cognitive task in humans (Bush, 2004) and in PCC cells during a cognitive task in monkeys (Hayden et al, 2009).

Interestingly, what Raichle and colleagues call 'deactivations' have also been called 'resting state activation' by others (Binder et al, 1999; Mazoyer et al, 2001). These latter groups view these internal/external monitoring processes as active processes, pointing out that the supposed resting state is not entirely passive, and often includes extraneous thoughts, memories, and emotions. These views are not mutually exclusive, as there are likely multiple processes contributing to higher $\mathrm{fMRI} / \mathrm{PET}$ activity during a resting state as compared with that seen during cognitive task performance. Although identifying the specific nature of these reciprocal reactions can be difficult (Buckner et al, 2008; Bush et al, 2000; Greicius and Menon, 2004; McKiernan et al, 2003), elucidating the nature of cognition-emotion-vigilance interactions will be vital to future understanding of ADHD pathophysiology.

\section{Selected ADHD Imaging Data}

As stated at the outset, the ADHD imaging literature has grown almost exponentially over the past three decades, and a comprehensive, critical review is beyond the scope of this paper. Such reviews can be found elsewhere (Bush, 2009; Bush et al, 2005; Casey et al, 2007b; Dickstein et al, 2006; Durston, 2003; Giedd et al, 2001; Nigg and Casey, 2005; Schneider et al, 2006; Seidman et al, 2004b, 2005; Spencer et al, 2005; Swanson et al, 2007; Valera et al, 2007). Instead, a selected highlighting of some relevant study will be provided here (1) to give a broad overview of the techniques that are being used to study ADHD, (2) to identify how the emerging data from these studies fits together to inform our current understanding of ADHD neurocircuitry, and (3) to provide a base from which to make suggestions about important trends to follow-up and a number of new possible avenues to explore in the future.

An important point of emphasis must be made at this juncture. Functional imaging techniques can broadly be divided into studies on: (1) pathophysiology, (2) treatment effects, and (3) potential aids in clinical diagnosis. Although functional imaging techniques hold future promise for testing for regional brain dysfunction in neuropsychiatric disorders, the field is not at the point where imaging can be recommended for any clinical purpose besides from ruling out medical/neurological causes from the differential diagnosis of ADHD (Bush, 2008). Functional and structural imaging studies generally use group-averaging and between-group statistical analyses, owing to the usually limited power to detect differences in individuals. Such group-based designs can be useful in studying both pathophysiology and medication effects, but clinical diagnostic decision-making requires the ability to reliably distinguish normal from abnormal, and ADHD from other disorders, at the individual subject level. No technique thus far has been proven and accepted in the peer-reviewed literature as having met this standard. Thus, at this time, besides helping to rule out medical or neurological causes for an ADHD-like presentation, it must be emphasized that no current imaging technique can be recommended for the purpose of aiding with the clinical diagnosis of ADHD.

Structural studies. Structural imaging, particularly morphometric/volumetric MRI, has shed light on our understanding of ADHD. These have generally helped establish that in ADHD, there are widespread abnormalities in the volumes of brain circuitry relevant to attention and 
motor control. In addition to relatively consistent findings of decreased total cerebral volume of $\sim 3$ to $5 \%$ (Castellanos, 2001; Castellanos et al, 1996, 2002; Seidman et al, 2005; Valera et al, 2007), volumetric studies have also found more specific abnormalities within defined regions of the lateral prefrontal cortex, cingulate cortex, striatum, cerebellum, and corpus callosum (Castellanos et al, 1996; Kates et al, 2002; Overmeyer et al, 2001; Semrud-Clikeman et al, 2000).

Smaller cingulate cortical volumes have been reported in adults (Seidman et al, 2006) and children (SemrudClikeman et al, 2006) with ADHD. An earlier study of ADHD children, relevant to default mode network studies, showed a reduction in posterior cingulate volume in ADHD (Overmeyer et al, 2001). Together, such studies illustrate the bidirectional flow of information: cognitive and affective neuroscience advances suggested particular regions should be tested, and in turn the ADHD findings provided examples of 'natural lesion' studies on these brain areas.

A number of studies have shown basal ganglia and cerebellar volumetric abnormalities. Globus pallidus has been shown to be smaller (Castellanos et al, 1996). Caudate studies have suggested smaller caudate in ADHD but have been inconsistent. Some have reported decreased volume of caudate in ADHD patients relative to controls (SemrudClikeman et al, 2006); Castellanos et al, 2002; Hynd et al, 1993), whereas others found no volume differences (Hill et al, 2003) or larger caudate in ADHD patients (Mataro et al, 1997). Castellanos et al (2002) indicated that initially smaller caudate volumes showed normalization in ADHD males during late adolescence, possibly reflecting the clinical observation that the hyperactivity of ADHD tends to diminish during this time. Prospective studies further examining this possibility, incorporating objective measures of hyperactivity, would be of interest. Multiple studies have reported structural abnormalities of the cerebellum in ADHD patients (Berquin et al, 1998; Castellanos et al, 2002; Mostofsky et al, 1998; Valera et al, 2007; Bledsoe et al, 2009). Overall, although some discrepancies exist, the weight of the evidence indicates that both global and regional volumetric abnormalities occur in ADHD.

Cortical (gray matter) thickness studies. Cortical thickness quantification through high-resolution MRI structural scans has been recently applied to the study on ADHD. Children with ADHD had significant global thinning of the cortex, most prominently in the medial and superior prefrontal and precentral regions (Shaw et al, 2006). These data in children were generally consistent with the findings Makris et al (2007) that showed selective cortical thinning of the CFP attention networks in adults with ADHD. Importantly, visà-vis the growing interest in possible contributions of the altered default mode network to ADHD pathophysiology, this study also reported cortical thinning of the PCC. However, cortical thickness results have not always been consonant. Wolosin et al (2009), although finding that children with ADHD displayed expected overall decreases of total cerebral and cortical volumes, and a significant decrease in cortical folding bilaterally, did not detect significant differences in cortical thickness between ADHD and healthy children.

The Shaw/NIMH group also reported delay in cortical thickness maturation in ADHD (Shaw et al, 2007a). These delays in ADHD were most prominent in the lateral prefrontal cortex, especially the superior and DLPFC regions. In a separate study combining cortical thickness and genetics, Shaw et al (2007b) reported that possession of the dopamine D4 receptor (DRD4) 7-repeat allele in healthy children and ADHD was associated with significant cortical thinning of multiple regions including the OFC, inferior prefrontal cortex, and posterior parietal cortex. These brain regions were generally thinner in ADHD patients than in controls, although the matter is complex as ADHD patients with the 7-repeat allele fared better clinically, suggesting further study is required.

Connection abnormalities: corpus callosum and DTI. The corpus callosum connects the two cerebral hemispheres, and callosal abnormalities might therefore affect interhemispheric communication in ADHD. Callosal volumetric reductions could reflect fewer axons and/or decreased axonal myelination, but could also secondarily indicate fewer cortical neurons within the regions connected by these fibers. Abnormalities of corpus callosum volume and morphometry have been reported many times in ADHD. There is some evidence indicating regional specificity, with anterior abnormalities including the genu (Hynd et al, 1991) and the rostral regions (Baumgardner et al, 1996; Giedd et al, 1994), suggesting abnormal prefrontal and premotor connections, as well as posterior abnormalities of the splenium (Hill et al, 2003; Hynd et al, 1991) and isthmus (Lyoo et al, 1996), suggesting parietal and temporal lobe connection problems. However, the area is not without controversy. Although meta-analysis by Valera et al (2007) reported reduced splenium volumes in children and adolescents with ADHD, a subsequent meta-analysis that agreed with Valera's main finding suggested that gender may have played a role, with smaller splenium in females with ADHD and smaller rostral body in boys with ADHD (Hutchinson et al, 2008). Together, these results indicate that callosal abnormalities exist in ADHD, but gender, age, and other factors need further study.

DTI, a relatively new MRI technique that permits assessment of the integrity of white matter tract connections, has recently been applied to studying ADHD. Fractional anisotropy (FA), an indicator of the non-random diffusion of water within axons, has been the most often used DTI measurement parameter. Ashtari et al (2005) reported children with ADHD had decreased FA in the premotor cortex, striatum, cerebellum, and left parietooccipital areas. Casey et al (2007a) used fMRI maps from a go/no-go task to identify portions of the VLPFC and striatum involved in suppressing an inappropriate action in parent-child dyads with and without ADHD. They reported FA in the right prefrontal fiber tracts was correlated with 
both functional activity in the inferior frontal gyrus and caudate nucleus and with performance of a go/no-go task in parent-child dyads with ADHD. Further, prefrontal fiber tract measures were associated between ADHD parents and their children, suggesting disruption of frontostriatal connections has a role in ADHD. Makris et al (2008) showed that abnormalities of the cingulum bundle and superior longitudinal fascicle II - connection pathways that subserve attention and executive functions - are evident in adults with ADHD. Lower corticospinal tract and superior longitudinal fasciculus FA (Hamilton et al, 2008) similarly suggested disruption of motor and attention networks in ADHD children, whereas the study by Silk et al (2008) indicated that fronto-striatal and fronto-parietal circuitry abnormalities exist in children with ADHD. Finally, pediatric samples showed decreased FA in the anterior corona radiata and abnormalities across multiple white matter tracts in ADHD, including the cingulum bundle, the superior and inferior longitudinal fasciculi, and internal capsule (Pavuluri et al, 2009). Together, the data argue that white matter abnormalities are associated with ADHD. However, more advanced methodology will be needed to determine whether these observed abnormalities are becuase of primary problems with the connecting tracts themselves, are secondary to pathology in the regions that the white matter tracts connect, or whether they reflect some combination of effects.

\section{Functional Studies: PET and fMRI}

Radioactivity-based techniques. Single-photon emission computed tomography (SPECT) and photon emission tomography (PET) are functional imaging studies that provide indirect measures of neuronal activity. Both SPECT and PET have generally been supplanted by fMRI for functional studies, as fMRI offers superior spatial and temporal resolution, and SPECT and PET's use of radiopharmaceuticals makes it ethically difficult to justify their use in healthy volunteers, especially children (Castellanos, 2002). However, both SPECT and PET still have important uses that other non-invasive techniques do not offer, such as neurotransmitter receptor characterization, measurement of dopamine transporter (DAT) levels, and quantification of extracellular dopamine (Madras et al, 2006; Spencer et al, 2006, 2005; Volkow et al, 2005, 2007). Early SPECT studies suggested striatal/basal ganglia abnormalities (Lou et al, 1984, 1990, 1989), despite some methodological issues (Castellanos, 2002). Another SPECT study showed that methylphenidate (MPH) increased $\mathrm{rCBF}$ in the DLPFC, caudate, and thalamus in previously treatment-naive children and adolescents with ADHD (Kim et al, 2002).

Zametkin et al (1990) were the first to publish a largescale, well-designed functional imaging study of ADHD. This PET study used [18F]fluoro-2-deoxy-D-glucose to measure cerebral glucose metabolism in 75 adult subjects (25 treatment-naive ADHD and 50 controls). They found that global cerebral glucose metabolism was $8.1 \%$ lower in the ADHD group and that even after normalization for these global decreases regional metabolism remained lower in the daMCC, premotor, and somatosensory areas. These findings are consistent with the structural data discussed above that indicate cerebral volume is lower in ADHD patients than in healthy controls. Fronto-temporal abnormalities during a working memory task in ADHD were found in another PET study (Schweitzer et al, 2000). Ernst et al (2003), employing a gambling task, provided data implicating the daMCC and VLPFC in ADHD and highlighting the need to further examine cognitive, emotional, and motivational interactions in its pathophysiology.

$f M R I$. fMRI, the newest of the major functional imaging methods, presents a number of advantages over both SPECT and PET for functional neurocircuitry studies. fMRI is noninvasive and does not require ionizing radiation. Thus, subjects can be scanned repeatedly, facilitating longitudinal, developmental, and pharmacoimaging studies. This ability to repeatedly scan the same subject multiple times enables 'functional dissections,' in which different tasks can be used to interrogate neural circuits. fMRI has superior spatial and temporal resolution, and tasks can be performed in either a blocked format or an event-related manner, which allows greater flexibility in task design. Newer arterial spin labeling (ASL) techniques can characterize brain activity during 'resting states' and other methods can identify functional connections between brain regions. Higher field strength magnets, coupled with specialized cognitive activation tasks, are able to produce brain maps in individual subjects, which have enabled characterization of drug effects in single subjects and analyses of intersubject variability (Bush et al, 2008). For these reasons, fMRI has become the dominant functional imaging modality used by psychiatric imaging researchers as well as cognitive and affective neuroscientists.

Regionally, the most consistent theme that has emerged has been the repeated finding of daMCC dysfunction. The daMCC normally has key roles in attention, cognition, motor control/response selection, motivation, error detection, and feedback-based decision-making (Bush, 2009; Bush et al, 2000, 2002; Vogt et al, 1992). Numerous fMRI, PET, and event-related potential (ERP) studies have reported daMCC hypofunction in ADHD, using various tasks and techniques (Bush et al, 1999; Durston et al, 2007, 2003a; Konrad et al, 2006; Liotti et al, 2005; Pliszka et al, 2006; Rubia et al, 1999; Smith et al, 2008; Tamm et al, 2004; Zametkin et al, 1990; Zang et al, 2005). Moreover, a metaanalysis of neuroimaging studies by Dickstein et al (2006) found the daMCC among a short list of brain regions that were hypoactive in ADHD patients relative to healthy controls. Recently, Bush et al (2008) used fMRI to show that 6 weeks of MPH significantly increased daMCC activation, as compared with placebo, in adults with ADHD. Similarly, an ERP study reported that stimulant treatment increased ACC activity (Pliszka et al, 2007). Clearly, the accumulated evidence from these fMRI, PET, and ERP studies, when 
combined with the cortical thickness and volumetric data reviewed above, provide a compelling argument that daMCC dysfunction contributes to ADHD.

Key confirmatory evidence indicating wider CFP neurocircuitry dysfunction in ADHD was provided by a voxelbased meta-analysis of 16 ADHD imaging studies by Dickstein et al (2006). The use of an activation likelihood estimate meta-analytic method (Lancaster et al, 2005) allowed a relatively unbiased overview of ADHD imaging findings. ADHD was found to be associated with significant hypoactivity of the daMCC, DLPFC, VLPFC, superior parietal cortex, caudate, and thalamus. Moreover, limiting the focus to studies on response inhibition tasks, as suggested by the study of Aron and Poldrack (2005) and Durston et al (2003a), identified a more limited set of regions, including the VLPFC, daMCC, parietal cortex, caudate, and precentral gyrus, but notably not the DLPFC. These data help resolve some surprising apparent inconsistencies observed with respect to lateral frontal cortical areas (DLPFC and VLPFC) in previous separate imaging studies. Thus, it appears that dysfunction of the DLPFC and VLPFC (Aron et al, 2003; Bush et al, 2005; Durston, 2003; Kobel et al, 2008; Pliszka et al, 2006; Schneider et al, 2006; Smith et al, 2008; Vaidya and Stollstorff, 2008) have important and separable roles in ADHD.

Caudate functional abnormalities were found in the above meta-analysis, just as they have been fairly consistently found with individual fMRI studies, especially when using response inhibition tasks, such as go/no-go or stop-signal tasks (Durston et al, 2003b; Epstein et al, 2007; Rubia et al, 1999; Vaidya et al, 1998). Vance et al (2007) also recently reported lower right caudate in ADHD during a mental rotation task. Lower resting putamen blood flow was reported in ADHD (Teicher et al, 2000) by a study that used T2 relaxometry, which is an indirect MRI measure of steady-state regional blood flow that pre-dates the more recent use of ASL techniques. Together, these data fit with the structural imaging findings, previous SPECT/PET studies, and the reports of DAT abnormalities found in the striatum discussed below.

The parietal cortex, although long known to have important roles in attention and spatial processing, has only more recently been the focus of ADHD imaging studies. Tamm et al (2006) reported ADHD subjects performing a visual oddball task showed significantly less activation of parietal cortical areas, including the superior parietal gyrus and multiple areas of inferior parietal lobe, along with the lower precuneus and thalamus activation. Vance et al (2007) reported that ADHD subjects performing a spatial working memory-dependent mental rotation task displayed significantly less inferior parietal lobe activation, in addition to lower parieto-occipital and caudate activation. In another study, children with ADHD showed less activation than controls in multiple areas of the parietal cortex, DLPFC, and putamen. A lack of a difference in the daMCC in this study may have been attributable higher error rates in the ADHD group, as errors activate the
daMCC (Cao et al, 2008). Parietal hypofunction has also been observed in ADHD in tasks of mental rotation/spatial processing (Silk et al, 2005), task switching (Smith et al, 2006) and sequential finger tapping (Mostofsky et al, 2006). Although it is clear that hypofunctioning parietal cortical subdivisions have roles in ADHD pathophysiology, the challenges ahead will be in specifically pinpointing how the various areas contribute to create the observed symptoms.

The cerebellum has increasingly gained recognition as part of disordered circuitry that underlies ADHD. As Schneider et al (2006) discuss, imaging studies have helped show that cerebellum has multiple complex roles beyond its traditional primary role in motor coordination. The study by Schmahmann has been particularly illuminating (Schmahmann and Caplan, 2006; Schmahmann and Sherman, 1998; Schmahmann et al, 2007), and a recent neuroimaging meta-analysis identified cerebellar contributions to various processes, including motor, somatosensory, language, verbal working memory, spatial processing, executive functions, and affective processing (Stoodley and Schmahmann, 2009). Substantial evidence of structural abnormalities of the cerebellum in ADHD has been presented above. In addition, a number of fMRI studies have identified functional abnormalities of the cerebellum in ADHD. Although more of the studies have reported decreased cerebellar activation in ADHD during task performance (Durston et al, 2007; Valera et al, 2005; Zang et al, 2005) or at rest (Anderson et al, 2002; Kim et al, 2002), others have reported increased activation in ADHD (Rubia et al, 2009; Schulz et al, 2004). It is anticipated that improved understanding of cerebellar contributions to various cognitive and affective functions, along with increasingly focused studies on cerebellum's potential role in ADHD, will help to shed light on this controversy.

Although abnormalities of the CFP cognitive/attention network, striatum, and cerebellum have figured most prominently in functional imaging studies on ADHD, other brain regions have been implicated by fMRI. Thalamic abnormalities have been found during active tasks (Dickstein et al, 2006; Tamm et al, 2006) and at rest (Zhu et al, 2008), and occipital cortex abnormalities have been identified (Dickstein et al, 2006; Valera et al, 2005). Differences in the temporal cortex between groups with ADHD and healthy controls have been noted during active tasks (Rubia et al, 2009; Smith et al, 2006; Vaidya et al, 2005). Contralateral motor cortex hypoactivity during motor sequencing has been reported (Mostofsky et al, 2006). Midbrain dysfunction in ADHD, as hypothesized by Castellanos (1997), and as reported by Ernst et al (1998) using a PET measure of dopa decarboxylase activity, can unfortunately be technically challenging to assess with fMRI due to the pulsatile motion of brainstem (Guimaraes et al, 1998 ) and possible differences in blood flow regulation in this area (Hart et al, 2006). However, given its potential role in ADHD pathophysiology, it is hoped that more prospective studies on midbrain will be performed, perhaps using 
advanced techniques such as cardiac-gated fMRI (Guimaraes et al, 1998).

Functional pharmacoimaging studies. Functional pharmacoimaging, by showing the ways in which drugs act on different brain regions, not only directly adds to the understanding of the mechanisms of drug effects but also indirectly helps to identify alterations in the neural circuitry that may underlie ADHD. An emerging literature of functional pharmacoimaging studies now suggests that the generally observed hypoactivation of the CFP cognitive/ attention network and the striatum in ADHD is counteracted by the medications used to treat ADHD. For the sake of discussion, this section will highlight the fronto-striatal effects using techniques other than dopaminergic-specific imaging studies, which will be discussed separately below.

Although a series of early PET studies on acute and chronic stimulant medication effects in ADHD (Ernst et al, 1994; Matochik et al, 1994, 1993) could not identify consistent brain responses, they laid the groundwork for subsequent studies on medication effects. Vaidya et al (1998), in an fMRI study of the effects of MPH on children performing go/no-go tasks, showed not only that frontostriatal activity differed between ADHD and healthy controls but also that the groups' responses to $\mathrm{MPH}$ differed. MPH increased prefrontal activation to an equal extent in both groups on one task, but on the other go/nogo task MPH increased striatal activation in the ADHD group while reducing striatal activation in healthy controls.

Studies using various techniques followed. A steady-state MRI-based method (T2 relaxometry) showed that in children with ADHD, MPH significantly changed blood flow to the putamen (Teicher et al, 2000) and cerebellar vermis (Anderson et al, 2002). SPECT studies, despite some limitations, also made contributions. One reported MPH increased $\mathrm{rCBF}$ in the DLPFC, caudate, and thalamus bilaterally in previously treatment-naive children and adolescents with ADHD (Kim et al, 2001). Another study showed medication withdrawal had measurable brain effects, highlighting the need to better define drug washout periods for both pharmacoimaging and pathophysiology studies (Langleben et al, 2002). A resting state PET study with scans performed 3 weeks apart found the offMPH condition was associated with relatively higher $\mathrm{rCBF}$ in the precentral gyri, caudate, and claustrum; whereas MPH increased $\mathrm{rCBF}$ in the cerebellar vermis (Schweitzer et al, 2003).

An fMRI study using a divided attention task reported that unmedicated subjects with ADHD recruited the left ventral basal ganglia less than did healthy controls, and $\mathrm{MPH}$ increased activation in this region (Shafritz et al, 2004). An acute MPH medication fMRI study showed MPH consistently (i.e., in both children and adults) produced increased activation of the caudate and cerebellum, along with inconsistent changes in other brain regions (Epstein et al, 2007). Pliszka et al (2007) using ERPs found that stimulant treatment increases ACC activity in ADHD.
Subsets of children from a long-term (1 year) fMRI study of ADHD found data suggestive of long-term MPH-induced changes in the insula, putamen, and cingulate cortex (Konrad et al, 2007).

A recent study by Bush et al (2008) used fMRI in conjunction with a specialized cognitive task, the MultiSource Interference Task (MSIT) (Bush and Shin, 2006), to determine whether an MPH preparation would increase activation in the daMCC and other fronto-parietal regions that subserve attention. This randomized, placebo-controlled, 6-week, pre/post study found a group $\times$ scan interaction and $t$-test confirmation of higher activation in the daMCC at 6 weeks in the MPH group, as compared with the placebo group. Moreover, use of the MSIT permitted single-subject daMCC volume-of-interest analyses that confirmed the group-averaged findings and suggested that daMCC activity might be related to clinical response. Beyond daMCC, 6 weeks of MPH also increased activation of many structures implicated in ADHD pathophysiology, including the DLPFC, VLPFC, parietal cortex, caudate, thalamus, and temporal lobe. These findings indicate that $\mathrm{MPH}$ may act, in part, by normalizing the daMCC and CFP hypofunction in ADHD. These data dovetail well with those from a recent MRS study that found decreased choline and increased $\mathrm{N}$-acetyl-aspartate (NAA) levels in the daMCC after treatment of ADHD with 5-6 weeks of MPH, indicating that biochemical changes occur in the daMCC with longer term MPH treatment (Kronenberg et al, 2008).

Non-stimulant medications for ADHD are just starting to be studied with fMRI in humans. Building on clinical and animal work, a recent contribution was made by Chamberlain et al (2009). Using fMRI, they showed that atomoxetine, a selective noradrenaline reuptake inhibitor used to treat ADHD, increased both inhibitory control on a stop-signal task and right VLPFC activation in healthy male adults. Given established VLPFC hypofunction in ADHD, it will be interesting to see in future studies if ADHD subjects respond to atomoxetine with a predicted VLPFC activation increase, and how ADHD brain responses to atomoxetine compare with responses to stimulants. Also, these data provide an excellent example of how ADHD research can also shed light on normal brain circuitry, as they provide a better understanding of response inhibition processes in healthy humans.

Resting state studies. Although the majority of functional imaging studies have concentrated on using various cognitive activation paradigms to specifically target different elements of the neural circuits subserving cognition, attention, and motor functions, growing interest has been noted in the use of techniques that focus on subjects' resting brain activity. Such resting studies are important as one of the main problems in ADHD may lie in dysfunction of brain regions that, as discussed above, support a proposed 'default network'. Specifically, it may be the case that an abnormally high default mode network activity may interfere with CFP attention network activity. 
One resting state PET study showed that MPH increased $\mathrm{rCBF}$ in the cerebellar vermis and was associated with decreased rCBF in the precentral gyri, caudate, and claustrum (Schweitzer et al, 2003), whereas another reported MPH potentiates dopaminergic activity in the striatum of adolescents with ADHD (Rosa-Neto et al, 2005). A series of resting state MRI studies has also provided insights into functional connectivity among brain regions, primarily fronto-cingulate-cerebellar circuits (Tian et al, 2006; Zang et al, 2006; Zhu et al, 2005). Later, resting state discriminative analysis indicated dysfunction of the daMCC, lateral prefrontal cortex, thalamus, and lateral parietal cortex in ADHD (Zhu et al, 2008), whereas Tian et al (2008) used resting state MRI to show that ADHD patients exhibited higher resting state activity in the lower-level sensory cortex, concluding that this was related to inattention. Interestingly, Castellanos et al (2008) identified reduced functional connectivity between the daMCC and default network structures (precuneus and PCC) and altered connectivity within default network itself (VMPFC, precuneus, and PCC) - findings that were essentially confirmed by the same group using a different network homogeneity model (Uddin et al, 2008). Work in this vein has been based on hypothesized interruption of attention network activity by altered default network activity (Weissman et al, 2006), which in ADHD has been thought to lead to greater variability in ADHD performance (Sonuga-Barke and Castellanos, 2007). ASL techniques, which can provide absolute measures of rCBF during rest (Aguirre et al, 2005; Detre and Wang, 2002; Kim et al, 2006; Wang et al, 2005) should help better define the pathophysiology of ADHD and other psychiatric disorders (Broyd et al, 2009).

Dopaminergic studies. Although this review focuses on neurocircuitry, it is illustrative to mention how work on dopaminergic modulatory functions can be integrated with neurocircuitry models. Imaging has increasingly been used to characterize the modulatory effects that different neurotransmitters may have on the brain circuits underlying ADHD. Dopamine has been of prime interest, given our although limited understanding of how it may increase neuronal signal-to-noise characteristics and its established roles in reward signaling. The interested reader can find reviews of the intricacies and debates surrounding dopaminergic imaging methods (Spencer et al, 2005; Swanson et al, 2007), as well as the roles various neurotransmitters may play in the pathophysiology of ADHD (Arnsten, 2001, 2006; Brennan and Arnsten, 2008) (Figure 2).

Dopamine has been a particular focus of ADHD research because in healthy humans it has roles on attention, cognition, and reward processes (Brennan and Arnsten, 2008; Schultz, 1998, 2006; Solanto, 2002). Dopamine can have both short-term phasic (milliseconds to seconds) and long-term tonic (minutes to hours) modulatory influences on CFP attention networks, meso-limbic circuitry, and fronto-cerebellar circuits. Dopaminergic modulation can increase the neuronal signal-to-noise ratio both by boosting

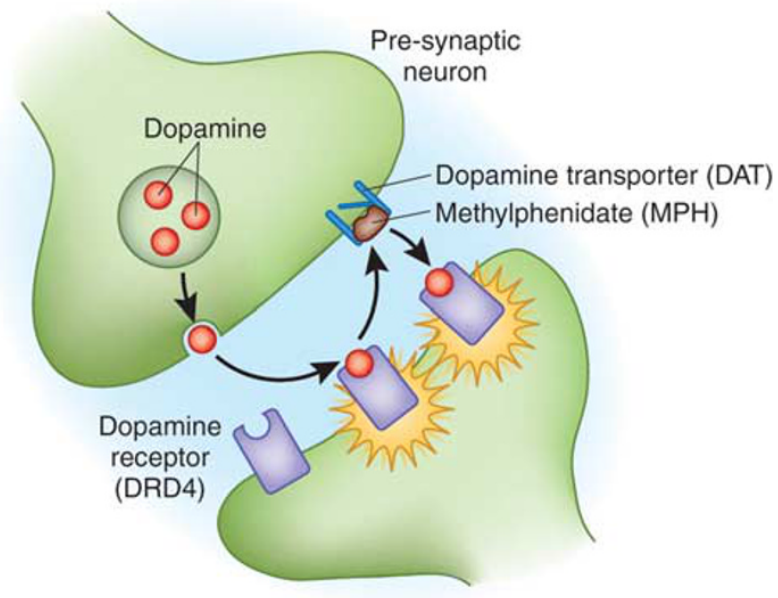

Figure 2. Dopamine synapse. Dopaminergic neurons release dopamine into the synapse, where it signals to post-synaptic neurons through specific receptors (illustrated here is the DRD4 receptor). Dopamine is then taken back into the presynaptic neuron through the dopamine transporter (DAT). Stimulants such as methylphenidate have been shown to block DAT, thus making more dopamine available in the extracellular space.

signal and by dampening background noise (Volkow et al, 2005). Dopamine also displays an inverted-U influence such that it optimizes neural transmission within a range but may adversely affect performance at lower or higher levels (Brennan and Arnsten, 2008).

Pioneering PET work by Volkow and colleagues has showed the specific activity of MPH's $d$-enantiomer in the basal ganglia (Ding et al, 1997), that oral MPH blocks the DAT with a time course matching behavioral effects (Volkow et al, 1998), and that MPH increases extracellular dopamine in the striatum (Volkow et al, 2001). Spencer et al (2006) have subsequently provided confirmatory PET data illustrating how striatal effects of MPH match behavioral effects using immediate and extended release formulations of MPH. Recent study in ADHD adults has also shown depressed dopamine activity in the caudate, and possibly some default network regions (amygdala/hippocampus) were associated with inattention (Volkow et al, 2007). Jucaite et al (2005) reported altered midbrain dopaminergic function in adolescents with ADHD, dovetailing well with previous midbrain dopamine abnormalities reported by Ernst et al (1999). Recent results have suggested neurotransmitter specificity, in that dopaminergic but not serotonergic transmitter reuptake was reduced in adults with ADHD (Hesse et al, 2009).

A related but contentious line of investigation involves the quantification of striatal DAT. As mentioned above, DAT is primarily responsible for presynaptic reuptake of dopamine, and it has been shown that MPH blocks DAT and increases extracellular dopamine (Spencer et al, 2005; Swanson et al, 2007; Volkow et al, 2002, 2005, 2007). Although initial reports found large (up to 70\%) increases in striatal DAT in ADHD (Dougherty et al, 1999; Krause 
et al, 2000), subsequent reports using different ligands and techniques have found lesser effect sizes, and in some cases, even lower DAT in ADHD (Volkow et al, 2007). Such discrepancies, which may be attributable to differences of ligands or imaging techniques used (Spencer et al, 2005; Volkow et al, 2007), will need to be resolved before firm conclusions about dopamine's role in ADHD can be made. Given this, in vivo imaging of dopaminergic function and modulation of the attention and reward networks would be lines of inquiry to follow.

Lastly, although these approaches have provided new information on possible mechanisms of stimulant medications used to treat ADHD at the synaptic and inter-cortical network levels, this should not be taken to suggest that dopamine is the only neurotransmitter relevant to ADHD. Instead, these recent advances should be seen as but the first waves of pharmacoimaging studies that will identify the ways that dopamine and other neurotransmitters (norepinephrine, acetylcholine, serotonin, glutamine and GABA) might modulate neurocircuitry implicated in causing ADHD.

\section{Future Research Directions}

Progress has been made in increasing our understanding of the neural circuitry of attention, cognition, and reward, as well as in applying that knowledge to elucidating both the pathophysiology of ADHD and the mechanisms by which treatments for ADHD work. The sections above have traced how observations of clinical phenomenology have been combined with cognitive neuroscience advances in the formulation of various models of ADHD. It has been shown that identifiable parallel distributed networks support different neural processes relevant to ADHD. For example, the CFP cognitive-attention network interacts with the striatum, premotor cortex, cerebellum, superior temporal sulcus, thalamus, and the brain stem reticular activating system to support cognitive-motor processing. Motivational information is encoded by reward regions including the striatum, daMCC, nucleus accumbens, and OFC. In healthy humans, these systems interact with one another and with default mode network regions (perigenual ACC, medial PFC, portions of VLPFC, amygdala, and PCC), which activate tonically during unstructured rest periods to support vigilance and internal state monitoring. Functional, structural, biochemical, and connectionist imaging data have varying degrees of illustrated abnormalities of brain regions within these functional systems, and pharmacoimaging has begun to identify precise ways in which medications used to treat ADHD exert their effects.

Still there is much unresolved. Outstanding neuroscientific questions include (1) what functions the individual CFP network regions and striatum perform during cognitive and reward processing, (2) how they interact with one another, and (3) how they might exert top-down control over lower processing modules. Dosenbach et al $(2008,2007)$ suggest that both separable fronto-parietal and cingulo-opercular subnetworks may modulate downstream processing activity, but that transient activity of the fronto-parietal network reflects trial-by-trial adjustments, whereas sustained activity of cingulo-opercular regions throughout trials may indicate that it is more responsible for set maintenance. Previous study has suggested that the DLPFC exerts top-down control early, whereas the cingulate cortex monitors performance (MacDonald et al, 2000). Dosenbach et al (2007) suggests that parallel 'hybrid' control systems are possible, which would be most consistent with the available data, although the exact mechanisms by which CFP networks act remain to be determined.

$\mathrm{ADHD}$ research is dependent on cognitive neuroscience to provide more specific answers as to the mechanisms of these processes, but as has been shown it can also push such basic research in certain directions. In turn, ADHD studies can enrich understanding of these processes and network interactions by providing sophisticated natural lesion studies. As ADHD is a heterogeneous, multi-factorial disorder (e.g., cognitive/attention system dysfunction in some, reward/motivation abnormalities in others, and perhaps intrusive default mode activity in others), opportunities for bidirectional influences between disciplines abound. These final sections will highlight some of the expected trends to follow and offer some suggestions for possible new avenues of research.

Resting state studies. Resting functional connectivity studies have recently formed a major trend in ADHD research and can provide valuable new information. Greater efforts to directly link such connectivity data with fMRI attention task and DTI connectivity data will be helpful. More importantly, the use of ASL techniques (Aguirre et al, 2005; Detre and Wang, 2002), which can provide absolute, as opposed to relative, measures of resting state brain activity, will be crucial to defining the relationships between cognitive, vigilance, and emotional circuits. Such ASL studies would provide uniquely important data not available from typical fMRI data sets nor resting state connectivity studies. Specifically, ASL studies would allow testing of the hypothesis that abnormally high default network activity interferes with normal CFP attention network activity in ADHD - a hypothesis suggested and supported by the study of Weissman et al (2006) and Sonuga-Barke and Castellanos (2007).

Need for different tasks and different foci. Replicating results using known and validated tasks is needed, but it will be equally if not more important to develop new tasks to make further headway in identifying the neurobiology of ADHD. As detailed above, established executive function and response inhibition tasks, including the Stroop and Stroop-like tasks, Flanker, go/no-go, and stop-signal tasks, and the MSIT have shed light on ADHD pathophysiology and treatment effects. However, newer and better tasks and techniques that focus attention on different brain regions are needed. 
For example, the use of existing tasks has revealed much about cingulo-fronto-striatal abnormalities, but other brain regions have been comparatively understudied. Parietal cortex is a prime example. Although it plays roles in attention and cognition and has therefore been implicated by a few studies, more spatial working memory task variants and other new paradigms specifically targeting parietal subregions should be used to test the integrity of parietal cortical areas in ADHD. Similarly, tasks can and should be developed that specifically test functioning of the OFC, cerebellum, midbrain, and thalamus. In related manner, motivational issues and their intersection with reward systems circuitry - including the striatum, nucleus accumbens, OFC, and daMCC - have theoretical and observed underpinnings that can be tied to known dopaminergic dysfunction in ADHD and must be fleshed out through new approaches. Interactions of emotional systems with attention/executive systems will be another important line of research.

It would be helpful if new tasks were designed that specifically focused on cognitive processes that have heretofore been underserved, such as vigilance or target detection functions. For example, continuous performance tasks have been used with limited success, but are inadequate to fully characterize vigilance and target detection. Pardo et al (1991) used a visual fixation dimming task that could be modified to study vigilance in ADHD. Alternatively, event-related fMRI might be used to characterize brain activity between widely spaced response trials that might capture neuronal lapses of attention or vigilance in a manner not confounded by motor responses. Such a task would support hypothesized attention impairments caused by inappropriate intrusion of default network activity, as proposed by Sonuga-Barke and Castellanos (2007).

More studies seeking to understand possible impairments of error processing in ADHD and individual performance differences would also be useful. These could consist of studies that explore the effects of variable performance on imaging data, both on mean differences between groups and on trial-to-trial variability within individual runs for a subject (Castellanos et al, 2005; Sonuga-Barke and Castellanos, 2007). Regardless of the task used, errors are intimately related to performance, and as discussed previously (Bush et al, 2005), error detection systems in the brain can have a profound impact on brain imaging results. Thus, error system signaling must be studied more prospectively and accounted for independent of task or data analysis techniques.

Variability analyses. Along with new foci of study must come novel study designs and statistical approaches. For example, traditional statistical comparisons emphasize looking for differences in means between groups while taking into account variability. Although mean differences are important, fMRI or ASL signal variability within subjects could be tested (perhaps by modified voxel-wise
Levene's tests for equality of variance between groups) and may turn out to be of great relevance to ADHD. Statistical comparisons of the 'noise' elements, which could be directly attributable to decreased dopamine levels that normally serve to dampen background neuronal firing noise, could additionally help evaluate apparent hypoactivation of ADHD groups (Bush et al, 1999). Future studies should therefore consider not only reporting statistical differences but also report means and variance of fMRI signal for subject samples through variability difference maps. Note that the noise comparisons may be in some cases related to previously hypothesized and observed findings on intraindividual variability due to lapses in attention (Castellanos et al, 2008; Sonuga-Barke and Castellanos, 2007), as neuronal noise characteristics may be independent of performance and may or may not vary within a scan.

Variability may manifest in other ways. Anatomic variability of brain structures makes region definition complex. Further complicating this fact is the suggestion from a recent study that ADHD brains may show greater degrees of anatomic variability than those of healthy controls (Bush et al, 2008). Such anatomic variability will need to be quantified and accounted for. Dopaminergic tests are also in some cases dependent on a cognitive state, and even 'resting' studies on DAT may be confounded, as controversy exists surrounding the definition of whether or not the healthy brain has a 'default resting state' or how to determine what mental activities are taking places when a subject is 'resting' (Raichle et al, 2001; Sonuga-Barke and Castellanos, 2007).

Multimodal imaging and technique refinement. The combined use of multiple techniques to study the same subject samples can reduce anatomical variability. It will also produce enriched data sets that will benefit from incorporating the relative strengths of some techniques while offsetting the weaknesses of the others. For example, fMRI has excellent spatial and fair temporal resolution, whereas ERPs (Barry et al, 2003; Liotti et al, 2005; Pliszka, 2007; Tannock, 1998) and magnetoencephalography (MEG) possess millisecond temporal resolution but relatively poor spatial resolution. Combined fMRI and electroencephalography (EEG) can also be used for cognitive or affective tasks (Menon and Crottaz-Herbette, 2005). It is anticipated that ADHD studies will increasingly combine fMRI with ERPs (Crottaz-Herbette and Menon, 2006), MEG, or EEG.

Other ways to improve such multi-level integration would be to combine fMRI with PET dopaminergic imaging techniques (Schott et al, 2008), connectivity techniques (such as DTI or other resting state connectivity techniques), or possibly with MRS measures of biochemical markers. For example, MRS has been used with some success to identify biochemical abnormalities in ADHD (Bush et al, 2005; Carrey et al, 2003; Courvoisie et al, 2004; Jin et al, 2001; Kronenberg et al, 2008; MacMaster et al, 2003; Perlov et al, 2007, 2008; Sun et al, 2005; Yeo et al, 2003), but has been limited because of previous requirements that restricted 
measurements to one or two a priori anatomical sites per study. More recently, although, chemical shift imaging techniques have been developed that can simultaneously measure the same MRS metabolites across whole brain, all within $\sim 15$ to $20 \mathrm{~min}$. Similar improvements will be likely for other existing techniques. DTI can be improved to better assess anatomical connections through greater resolution of crossing fiber tracts. Better dopaminergic imaging would permit more sensitive and reproducible DAT findings, and could include enhanced dopamine release study methods that would allow addressing of tonic versus phasic release issues (Duzel et al, 2009; Goldstein et al, 2009). Improved PET receptor characterization studies would permit in vivo dopamine receptor identification, which could synergistically improve functional and connectivity studies by refining our understanding of neuromodulatory effects. Better measures of other neurotransmitters, including noradrenergic, cholinergic, serotonergic, glutamatergic, and GABAergic systems, will similarly aid ADHD research. Although such technological improvements will occur with time, current efforts may be improved simply using batteries of tasks to study already well-characterized patient samples. Individual studies on single tasks, such as cognitive interference, target detection, vigilance, response inhibition, or working memory tasks, are certainly useful. However, such approaches only test a specific cognitive domain, and will not provide a comprehensive assessment of ADHD patients. Batteries of imaging tests can interrogate different aspects of neural circuits while simultaneously cutting down on anatomical variability and study costs.

Genetic studies. Genetic influences on the neural circuitry of attention need to be explored further. Work has already been published that begins to link genotype and/or familial linkage with structural findings in ADHD (Casey et al, 2007a; Monuteaux et al, 2008; Shaw et al, 2007b) and to cognitive/executive function in healthy humans (Fan et al, 2003). Koten et al (2009) recently reported data from healthy twins that are very relevant to $\mathrm{ADHD}$, as they showed how specific genetic factors could affect fMRI activation patterns within the brain regions of the CFP cognitive/attention network. Thus, genetic studies, as discussed recently (Durston, 2008; Greene et al, 2008; Rapoport and Shaw 2008), should be encouraged.

Clinical, translational and developmental issues. Many other factors will need to be addressed before fully characterizing the neurobiology of ADHD. The neural substrate of clinical subtypes will have to be determined, as ADHD is heterogeneous and likely to be associated with multiple causations. Some patients may have dopaminergic, noradrenergic, serotonergic, or cholinergic abnormalities, whereas others may show prominent genetic-based structural abnormalities. Still others may have disordered cortico-cortical connections. Moreover, each of these groups may have a different imaging profile. A related accounting must be made for phenomenological sub-types of $\mathrm{ADHD}$, as it is likely that inattentive, hyperactive, and combined sub-types have distinct neuroimaging features.

Imaging findings must be viewed from a refined developmental perspective, requiring more longitudinal structural, functional, and biochemical studies to be performed. Previous examples of structural studies generating hypotheses have been offered, such as normalization of caudate volumes in adolescence (Castellanos et al, 2002) potentially being responsible for the lack of hyperactivity in adults. Previous developmental study on the maturation of attention/CFP networks (Casey et al, 2005; Fair et al, 2007), reward circuitry (Galvan et al, 2006), and resting state networks (Fair et al, 2008) will also help inform ADHD studies. Follow-up studies are needed to determine the neural basis for why ADHD does or does not persist into adulthood in different cases.

Pharmacoimaging. Imaging has begun to characterize stimulant effects, but more studies are need to follow-up on these preliminary findings and to compare the mechanisms of action of different treatments. Beyond simply studying drugs although, it will be important to also identify the neural effects of alternative treatments such as cognitive-behavioral therapy, meditation, and yoga - all of which can affect the cognitive and emotional brain circuitry in powerful ways. Large-scale databases of imaging data, including cross-cultural studies, would also be helpful additions to the literature. Potential confounds, such as anxiety, substance abuse, effects of other medications, caffeine, IQ, brain laterality effects, and motivational status, will need to be accounted for, and ADHD must be differentiated from other disorders that display attention dysfunction, such as schizophrenia or depression. Such studies will undoubtedly have bidirectional beneficial effects.

Imaging studies face a number of challenges. Owing to their relatively high expense, sample sizes have tended to be small. Such underpowering renders them particularly susceptible to both type I and type II errors, which may also account for a number of the inconsistencies among studies. These limitations and many others have been reviewed at length elsewhere (Bush et al, 2005; Castellanos, 2002), and many other hurdles must still be overcome before functional imaging can be clinically useful (Bush, 2008). Collectively although, functional, structural, and biochemical neuroimaging techniques have begun fulfilling their promise as tools for defining both the neural circuitry of attention and the neurobiology of ADHD.

\section{ACKNOWLEDGEMENTS}

The author thanks Jennifer Space, Scott Rauch, Michael Jenike, Michael Posner, Brent Vogt, Joseph Biederman, Thomas Spencer, and the MGH Pediatric Psychopharmacology Clinic staff for invaluable assistance, support, mentoring, and collaboration related to the topics discussed 
herein; as well as the anonymous reviewers for their many helpful comments.

\section{DISCLOSURE}

This review was produced without direct support or compensation. Indirect support has been provided to the author for ADHD-related work over the past decade in the form of grant or general support by the National Institutes of Mental Health, the National Science Foundation, the Mental Illness and Neuroscience Discovery (MIND) Institute, the National Alliance for Research on Schizophrenia and Depression (NARSAD), the Benson-Henry Institute for Mind-Body Medicine at Massachusetts General Hospital, the McIngvale Fund, the Johnson and Johnson Center for the Study of Psychopathology, the Center for Functional Neuroimaging Technologies (P41RR14075), McNeil Pharmaceuticals, Pfizer Pharmaceuticals, and Eli Lilly \& Co. The author has, or has had in the past, a relationship with one or more organizations listed below as follows: former advisory board member and speaker's honoraria from Eli Lilly and Co. and Novartis Pharmaceuticals; and has received speaker's honoraria from Shire US Inc., Janssen Pharmaceuticals, Johnson \& Johnson, and McNeil Pharmaceuticals. The author does not now and has not at any time had a financial interest in any of these entities.

\section{REFERENCES}

Aguirre GK, Detre JA, Wang J (2005). Perfusion fMRI for functional neuroimaging. Int Rev Neurobiol 66: 213-236.

Alderson RM, Rapport MD, Kofler MJ (2007). Attention-deficit/hyperactivity disorder and behavioral inhibition: a meta-analytic review of the stop-signal paradigm. J Abnorm Child Psychol 35: 745-758.

Alexander GE, DeLong MR, Strick PL (1986). Parallel organization of functionally segregated circuits linking basal ganglia and cortex. Annu Rev Neurosci 9 357-381. A classic paper illustrating parallel distributed processing neural circuitry principles.

Allman JM, Hakeem A, Erwin JM, Nimchinsky E, Hof P (2001). The anterior cingulate cortex. The evolution of an interface between emotion and cognition. Ann NY Acad Sci 935: 107-117.

Allport DA (1980). Attention and performance. In: Claxton G (ed). Cognitive Psychology: New Directions. Routledge \& Kegan Paul: London. pp 112-153.

Allport DA (1987). Selection for action: some behavioral and neurophysiological considerations of attention and action. In: Heuer $\mathrm{H}$, Sanders AF (eds). Perspectives on Perception and Action. Lawrence Erlbaum Associates: Hillsdale, NJ. pp 395-419.

American Psychiatric Association (2000). Diagnostic and Statistical Manual of Mental Disorders - 4th Edition-Text Revision. American Psychiatric Press: Washington, DC.

Anderson CM, Polcari A, Lowen SB, Renshaw PF, Teicher MH (2002). Effects of methylphenidate on functional magnetic resonance relaxometry of the cerebellar vermis in boys with ADHD. Am J Psychiatry 159: 1322-1328.

Antrobus JS, Singer JL, Greenberg S (1966). Studies in the stream of consciousness: experimental enhancement and suppression of spontaneous cognitive processes. Percept Mot Skills 23: 399-417.

Arnsten AF (2001). Modulation of prefrontal cortical-striatal circuits: relevance to therapeutic treatments for Tourette syndrome and attention-deficit hyperactivity disorder. Adv Neurol 85: 333-341.

Arnsten AF (2006). Stimulants: therapeutic actions in ADHD. Neuropsychopharmacology 31: 2376-2383.

Arnsten AF, Dudley AG (2005). Methylphenidate improves prefrontal cortical cognitive function through alpha2 adrenoceptor and dopamine D1 receptor actions: relevance to therapeutic effects in Attention Deficit Hyperactivity Disorder. Behav Brain Funct 1: 2.
Aron AR, Fletcher PC, Bullmore ET, Sahakian BJ, Robbins TW (2003). Stop-signal inhibition disrupted by damage to right inferior frontal gyrus in humans. Nat Neurosci 6: 115-116.

Aron AR, Poldrack RA (2005). The cognitive neuroscience of response inhibition: relevance for genetic research in attention-deficit/hyperactivity disorder. Biol Psychiatry 57: 1285-1292.

Ashtari M, Kumra S, Bhaskar SL, Clarke T, Thaden E, Cervellione KL. et al (2005). Attention-deficit/hyperactivity disorder: a preliminary diffusion tensor imaging study. Biol Psychiatry 57: 448-455.

Badgaiyan RD, Posner Ml (1998). Mapping the cingulate cortex in response selection and monitoring. Neuroimage 7: 255-260.

Barkley RA (1990). Attention Deficit Hyperactivity Disorder: A Handbook for Diagnosis and Treatment. Guilford Press: New York.

Barkley RA (1997). Behavioral inhibition, sustained attention, and executive functions: constructing a unifying theory of ADHD. Psychol Bull 121: 65-94. Highly influential paper that modeled ADHD as a disorder of response inhibition.

Barkley RA, Grodzinsky G, DuPaul GJ (1992). Frontal lobe functions in attention deficit disorder with and without hyperactivity: a review and research report. J Abnorm Child Psychol 20: 163-188.

Barry RJ, Johnstone SJ, Clarke AR (2003). A review of electrophysiology in attention-deficit/hyperactivity disorder: II Event-related potentials. Clin Neurophysiol 114: 184-198.

Baumgardner TL, Singer HS, Denckla MB, Rubin MA, Abrams MT, Colli MJ et al (1996). Corpus callosum morphology in children with Tourette syndrome and attention deficit hyperactivity disorder. Neurology 47: 477-482.

Bechara A, Damasio H, Damasio AR (2000). Emotion, decision making and the orbitofrontal cortex. Cereb Cortex 10: 295-307.

Berman R, Colby C (2008). Attention and active vision. Vision Res 49: 1233-1248. Berquin PC, Giedd JN, Jacobsen LK, Hamburger SD, Krain AL, Rapoport JL et al (1998). Cerebellum in attention-deficit hyperactivity disorder: a morphometric MRI study. Neurology 50: 1087-1093.

Biederman $J$ (2004). Impact of comorbidity in adults with attention-deficit/ hyperactivity disorder. J Clin Psychiatry 65(Suppl 3): 3-7.

Biederman J, Faraone SV (2005). Attention-deficit hyperactivity disorder. Lancet 366: 237-248.

Binder JR, Frost JA, Hammeke TA, Bellgowan PS, Rao SM, Cox RW (1999). Conceptual processing during the conscious resting state. A functional MRI study. J Cogn Neurosci 11: 80-95.

Bledsoe J, Semrud-Clikeman M, Pliszka SR (2009). A magnetic resonance imaging study of the cerebellar vermis in chronically treated and treatment-naive children with attention-deficit/hyperactivity disorder combined type. Biol Psychiatry 65 620-624.

Brennan AR, Arnsten AF (2008). Neuronal mechanisms underlying attention deficit hyperactivity disorder: the influence of arousal on prefrontal cortical function. Ann NY Acad Sci 1129: 236-245.

Bronowski J (ed) (1977). Human and Animal Languages. MIT Press: Cambridge, MA.

Broyd SJ, Demanuele C, Debener S, Helps SK, James CJ, Sonuga-Barke EJ (2009). Default-mode brain dysfunction in mental disorders: a systematic review. Neurosci Biobehav Rev 33: 279-296.

Buckner RL, Andrews-Hanna JR, Schacter DL (2008). The brain's default network: anatomy, function, and relevance to disease. Ann NY Acad Sci 1124: 1-38. Comprehensive review of recent work related to a proposed default network of the brain that is more active during rest or low cognitive loads.

Bush G (2004). Multimodal studies of cingulate cortex. In: Posner MI (ed). Cognitive Neuroscience of Attention. Guilford Press: New York. pp 207-218.

Bush G (2008). Neuroimaging of attention deficit hyperactivity disorder: can new imaging findings be integrated in clinical practice? Child Adolesc Psychiatr Clin N Am 17: 385-404, $\mathrm{x}$.

Bush $G$ (2009). Dorsal anterior midcingulate cortex: roles in normal cognition and disruption in attention-deficit/hyperactivity disorder. In: Vogt BA (ed). Cingulate Neurobiology and Disease. Oxford University Press: New York, NY. pp 245-274.

Bush G, Frazier JA, Rauch SL, Seidman LJ, Whalen PJ, Jenike MA et al (1999). Anterior cingulate cortex dysfunction in attention-deficit/hyperactivity disorder revealed by $\mathrm{fMRl}$ and the Counting Stroop. Biol Psychiatry 45: 1542-1552.

Bush G, Luu P, Posner Ml (2000). Cognitive and emotional influences in anterior cingulate cortex. Trends Cogn Sci 4: 215-222. Review and meta-analyses of cingulate cortex contributions to cognition and emotion, highlighted functionally reciprocal responses of cingulate subdivisions.

Bush G, Shin LM (2006). The multi-source interference task: an fMRI task that reliably activates the cingulo-frontal-parietal cognitive/attention network in individual subjects. Nat Protoc 1: 308-313.

Bush G, Spencer TJ, Holmes J, Shin LM, Valera E, Seidman LJ et al (2008). Functional magnetic resonance imaging of methylphenidate and placebo in 
attention-deficit/hyperactivity disorder during the multi-source interference task. Arch Gen Psychiatry 65: 102-114. Recent fMRI work that showed methylphenidate increases activation of cingulo-frontal-parietal circuitry in ADHD via group and single subject data.

Bush G, Valera EM, Seidman LJ (2005). Functional neuroimaging of attentiondeficit/hyperactivity disorder: a review and suggested future directions. Biol Psychiatry 57: 1273-1284.

Bush G, Vogt BA, Holmes J, Dale AM, Greve D, Jenike MA et al (2002). Dorsal anterior cingulate cortex: a role in reward-based decision making. Proc Natl Acad Sci USA 99: 523-528.

Bush G, Whalen PJ, Rosen BR, Jenike MA, Mclnerney SC, Rauch SL (1998). The counting Stroop: an interference task specialized for functional neuroimaging - validation study with functional MRI. Hum Brain Mapp 6: 270-282.

Cabeza R, Nyberg L (2000). Imaging cognition II: an empirical review of 275 PET and fMRI studies. J Cogn Neurosci 12: 1-47.

Cao Q, Zang Y, Zhu C, Cao X, Sun L, Zhou Xet al (2008). Alerting deficits in children with attention deficit/hyperactivity disorder: event-related $\mathrm{PMRI}$ evidence. Brain Res 1219: 159-168.

Carrey N, MacMaster FP, Fogel J, Sparkes S, Waschbusch D, Sullivan S et al (2003). Metabolite changes resulting from treatment in children with ADHD: a $1 \mathrm{H}-$ MRS study. Clin Neuropharmacol 26: 218-221.

Casey BJ, Castellanos FX, Giedd JN, Marsh WL, Hamburger SD, Schubert AB et al (1997a). Implication of right frontostriatal circuitry in response inhibition and attention-deficit/hyperactivity disorder. J Am Acad Child Adolesc Psychiatry 36: 374-383.

Casey BJ, Epstein JN, Buhle J, Liston C, Davidson MC, Tonev ST et al (2007a). Frontostriatal connectivity and its role in cognitive control in parent-child dyads with ADHD. Am J Psychiatry 164: 1729-1736.

Casey BJ, Nigg JT, Durston S (2007b). New potential leads in the biology and treatment of attention deficit-hyperactivity disorder. Curr Opin Neurol 20: 119-124.

Casey BJ, Tottenham N, Liston C, Durston S (2005). Imaging the developing brain: what have we learned about cognitive development? Trends Cogn Sci 9: 104-110. Recent review illustrating progress in understanding developmental issues pertaining to cognitive processes.

Casey BJ, Trainor R, Giedd J, Vauss Y, Vaituzis CK, Hamburger S et al (1997b). The role of the anterior cingulate in automatic and controlled processes: a developmental neuroanatomical study. Dev Psychobio/ 30: 61-69.

Castellanos FX (1997). Toward a pathophysiology of attention-deficit/hyperactivity disorder. Clin Pediatr (Phila) 36: 381-393.

Castellanos FX (2001). Neural substrates of attention-deficit hyperactivity disorder. Adv Neurol 85: 197-206.

Castellanos FX (2002). Proceed, with caution: SPECT cerebral blood flow studies of children and adolescents with attention deficit hyperactivity disorder. J Nucl Med 43: $1630-1633$.

Castellanos FX, Giedd JN, Marsh WL, Hamburger SD, Vaituzis AC, Dickstein DP et al (1996). Quantitative brain magnetic resonance imaging in attention-deficit hyperactivity disorder. Arch Gen Psychiatry 53: 607-616.

Castellanos FX, Lee PP, Sharp W, Jeffries NO, Greenstein DK, Clasen LS et al (2002). Developmental trajectories of brain volume abnormalities in children and adolescents with attention-deficit/hyperactivity disorder. JAMA 288: 1740-1748. Large-scale study illustrating key structural abnormalities associated with ADHD in youth controlling for age, gender and medication exposure.

Castellanos FX, Margulies DS, Kelly C, Uddin LQ, Ghaffari M, Kirsch A et al (2008). Cingulate-precuneus interactions: a new locus of dysfunction in adult attentiondeficit/hyperactivity disorder. Biol Psychiatry 63: 332-337.

Castellanos FX, Sonuga-Barke EJ, Milham MP, Tannock R (2006). Characterizing cognition in ADHD: beyond executive dysfunction. Trends Cogn Sci 10: 117-123.

Castellanos FX, Sonuga-Barke EJ, Scheres A, Di Martino A, Hyde C, Walters JR (2005). Varieties of attention-deficit/hyperactivity disorder-related intra-individual variability. Biol Psychiatry 57: 1416-1423.

Chamberlain SR, Hampshire A, Muller U, Rubia K, Del Campo N, Craig K et al (2009). Atomoxetine modulates right inferior frontal activation during inhibitory control: a pharmacological functional magnetic resonance imaging study. Biol Psychiatry 65: 550-555.

Chess S (1960). Diagnosis and treatment of the hyperactive child. NY State J Med 60: 2379-2385.

Coghill D, Nigg J, Rothenberger A, Sonuga-Barke E, Tannock R (2005). Whither causal models in the neuroscience of ADHD? Dev Sci 8: 105-114.

Colby CL (1991). The neuroanatomy and neurophysiology of attention. J Child Neurol 6(Suppl): S90-S118.

Colby CL, Goldberg ME (1999). Space and attention in parietal cortex. Annu Rev Neurosci 22: 319-349.
Corbetta M (1998). Frontoparietal cortical networks for directing attention and the eye to visual locations: identical, independent, or overlapping neural systems? Proc Natl Acad Sci USA 95: 831-838. Synthetic paper that shows the neural bases for frontoparietal control of attention and oculomotor functions.

Corbetta M, Akbudak E, Conturo TE, Snyder AZ, Ollinger JM, Drury HA et al (1998). A common network of functional areas for attention and eye movements. Neuron 21: $761-773$.

Corbetta M, Kincade JM, Ollinger JM, McAvoy MP, Shulman GL (2000). Voluntary orienting is dissociated from target detection in human posterior parietal cortex. Nat Neurosci 3: 292-297.

Corbetta M, Kincade JM, Shulman GL (2002). Neural systems for visual orienting and their relationships to spatial working memory. J Cogn Neurosci 14: 508-523.

Corbetta M, Miezin FM, Dobmeyer S, Shulman GL, Petersen SE (1991). Selective and divided attention during visual discriminations of shape, color, and speed: functional anatomy by positron emission tomography. J Neurosci 11: 2383-2402.

Corbetta M, Patel G, Shulman GL (2008). The reorienting system of the human brain: from environment to theory of mind. Neuron 58: 306-324.

Courvoisie H, Hooper SR, Fine C, Kwock L, Castillo M (2004). Neurometabolic functioning and neuropsychological correlates in children with ADHD-H: preliminary findings. J Neuropsychiatry Clin Neurosci 16: 63-69.

Crottaz-Herbette S, Menon V (2006). Where and when the anterior cingulate cortex modulates attentional response: combined fMRI and ERP evidence. J Cogn Neurosci 18: 766-780.

Culham J (2002). Dissociations within association cortex. Neuron 33: 318-320.

Culham JC, Kanwisher NG (2001). Neuroimaging of cognitive functions in human parietal cortex. Curr Opin Neurobiol 11: 157-163.

Damasio AR (2001). Descartes' error revisited. J Hist Neurosci 10: 192-194.

Davidson RJ (2001). Toward a biology of personality and emotion. Ann NY Acad Sci 935: 191-207.

Davis M, Whalen PJ (2001). The amygdala: vigilance and emotion. Mol Psychiatry 6: $13-34$

Dehaene S, Kerszberg M, Changeux JP (1998). A neuronal model of a global workspace in effortful cognitive tasks. Proc Natl Acad Sci USA 95: 14529-14534.

Denckla MB (1989). Executive function, the overlap zone between attention-deficit/ hyperactivity disorder and learning disabilities. Int Pediatr 4: 155-160.

Denhoff E, Laufer MW, Solomons G (1957). Hyperkinetic impulse disorder in children's behavior problems. Psychosom Med 19: 38-49.

Detre JA, Wang J (2002). Technical aspects and utility of fMRI using BOLD and ASL. Clin Neurophysiol 113: 621-634.

Devinsky O, Morrell MJ, Vogt BA (1995). Contributions of anterior cingulate cortex to behaviour. Brain 118(Partt 1): 279-306.

Dickstein SG, Bannon K, Xavier Castellanos F, Milham MP (2006). The neural correlates of attention deficit hyperactivity disorder: an ALE meta-analysis. J Child Psychol Psychiatry 47: 1051-1062. A meta-analysis of functional neuroimaging studies that identified dysfunction of CFP-network structures, basal ganglia and thalamus across studies.

Ding YS, Fowler JS, Volkow ND, Dewey SL, Wang GJ, Logan J et al (1997). Chiral drugs: comparison of the pharmacokinetics of [11C]d-threo and L-threomethylphenidate in the human and baboon brain. Psychopharmacology (Berl) 131: 71-78.

Donnelly M, Haby MM, Carter R, Andrews G, Vos T (2004). Cost-effectiveness of dexamphetamine and methylphenidate for the treatment of childhood attention deficit hyperactivity disorder. Aust NZ J Psychiatry 38: 592-601.

Dosenbach NU, Fair DA, Cohen AL, Schlaggar BL, Petersen SE (2008). A dualnetworks architecture of top-down control. Trends Cogn Sci 12: 99-105.

Dosenbach NU, Fair DA, Miezin FM, Cohen AL, Wenger KK, Dosenbach RA et al (2007). Distinct brain networks for adaptive and stable task control in humans. Proc Natl Acad Sci USA 104: 11073-11078.

Dougherty DD, Bonab AA, Spencer TJ, Rauch SL, Madras BK, Fischman AJ (1999). Dopamine transporter density in patients with attention deficit hyperactivity disorder. Lancet $\mathbf{3 5 4}$ : 2132-2133.

Douglas VI (ed) (1988). Cognitive Deficits in Children with Attention Deficit Disorder with Hyperactivity. Pergamon: London.

Drevets WC, Raichle ME (1998). Reciprocal suppression of regional cerebral blood flow during emotional versus higher cognitive processes: implications for interactions between emotion and cognition. Cogn Emot 12: 353-385.

Duncan J, Owen AM (2000). Common regions of the human frontal lobe recruited by diverse cognitive demands. Trends Neurosci 23: 475-483.

Durston $S$ (2003). A review of the biological bases of ADHD: what have we learned from imaging studies? Ment Retard Dev Disabil Res Rev 9: 184-195. 
Durston S (2008). Converging methods in studying attention-deficit/hyperactivity disorder: what can we learn from neuroimaging and genetics? Dev Psychopathol 20: 1133-1143.

Durston S, Davidson MC, Mulder MJ, Spicer JA, Galvan A, Tottenham N et al (2007). Neural and behavioral correlates of expectancy violations in attentiondeficit hyperactivity disorder. J Child Psychol Psychiatry 48: 881-889.

Durston S, Davidson MC, Thomas KM, Worden MS, Tottenham N, Martinez A et al (2003a). Parametric manipulation of conflict and response competition using rapid mixed-trial event-related fMRI. Neuroimage 20: 2135-2141.

Durston S, Tottenham NT, Thomas KM, Davidson MC, Eigsti IM, Yang Y et al (2003b). Differential patterns of striatal activation in young children with and without ADHD. Biol Psychiatry 53: 871-878.

Duzel E, Bunzeck N, Guitart-Masip M, Wittmann B, Schott BH, Tobler PN (2009). Functional imaging of the human dopaminergic midbrain. Trends Neurosci 32: 321-328.

Epstein JN, Casey BJ, Tonev ST, Davidson MC, Reiss AL, Garrett A et al (2007). ADHD- and medication-related brain activation effects in concordantly affected parent-child dyads with ADHD. J Child Psychol Psychiatry 48: 899-913.

Ernst M, Kimes AS, London ED, Matochik JA, Eldreth D, Tata S et al (2003). Neural substrates of decision making in adults with attention deficit hyperactivity disorder. Am J Psychiatry 160: 1061-1070.

Ernst M, Zametkin AJ, Matochik JA, Jons PH, Cohen RM (1998). DOPA decarboxylase activity in attention deficit hyperactivity disorder adults. A [fluorine-18]fluorodopa positron emission tomographic study. J Neurosci 18: 5901-5907.

Ernst M, Zametkin AJ, Matochik JA, Liebenauer L, Fitzgerald GA, Cohen RM (1994). Effects of intravenous dextroamphetamine on brain metabolism in adults with attention-deficit hyperactivity disorder (ADHD). Preliminary findings. Psychopharmacol Bull 30: 219-225.

Ernst M, Zametkin AJ, Matochik JA, Pascualvaca D, Jons PH, Cohen RM (1999). High midbrain [18F]DOPA accumulation in children with attention deficit hyperactivity disorder. Am J Psychiatry 156: 1209-1215.

Fair DA, Cohen AL, Dosenbach NU, Church JA, Miezin FM, Barch DM et al (2008). The maturing architecture of the brain's default network. Proc Natl Acad Sci USA 105: 4028-4032.

Fair DA, Dosenbach NU, Church JA, Cohen AL, Brahmbhatt S, Miezin FM et al (2007). Development of distinct control networks through segregation and integration. Proc Natl Acad Sci USA 104: 13507-13512.

Fan J, Fossella J, Sommer T, Wu Y, Posner Ml (2003). Mapping the genetic variation of executive attention onto brain activity. Proc Natl Acad Sci USA 100: 7406-7411.

Fan J, McCandliss BD, Fossella J, Flombaum Jl, Posner MI (2005). The activation of attentional networks. Neuroimage 26: 471-479.

Fan J, McCandliss BD, Sommer T, Raz A, Posner MI (2002). Testing the efficiency and independence of attentional networks. J Cogn Neurosci 14: 340-347.

Fan J, Posner M (2004). Human attentional networks. Psychiatr Prax 31(Suppl 2): S210-S214.

Faraone SV, Biederman J (2005). What is the prevalence of adult ADHD? Results of a population screen of 966 adults. J Atten Disord 9: 384-391.

Faraone SV, Biederman J, Mick E (2006). The age-dependent decline of attention deficit hyperactivity disorder: a meta-analysis of follow-up studies. Psychol Med 36: 159-165.

Fox MD, Corbetta M, Snyder AZ, Vincent JL, Raichle ME (2006). Spontaneous neuronal activity distinguishes human dorsal and ventral attention systems. Proc Natl Acad Sci USA 103: 10046-10051.

Fuster JM (1989. The Prefrontal Cortex. Raven Press: New York.

Galvan A, Hare TA, Davidson M, Spicer J, Glover G, Casey BJ (2005). The role of ventral frontostriatal circuitry in reward-based learning in humans. J Neurosci 25: 8650-8656.

Galvan A, Hare TA, Parra CE, Penn J, Voss H, Glover G et al (2006). Earlier development of the accumbens relative to orbitofrontal cortex might underlie risk-taking behavior in adolescents. J Neurosci 26: 6885-6892.

Gehring WJ, Fencsik DE (2001). Functions of the medial frontal cortex in the processing of conflict and errors. J Neurosci 21: 9430-9437.

Giedd JN, Blumenthal J, Molloy E, Castellanos FX (2001). Brain imaging of attention deficit/hyperactivity disorder. Ann NY Acad Sci 931: 33-49.

Giedd JN, Castellanos FX, Casey BJ, Kozuch P, King AC, Hamburger SD et al (1994). Quantitative morphology of the corpus callosum in attention deficit hyperactivity disorder. Am J Psychiatry 151: 665-669.

Goldman-Rakic PS (1988). Topography of cognition: parallel distributed networks in primate association cortex. Annu Rev Neurosci 11: 137-156. A review paper that identified multiple PDP networks supporting cognitive processes.
Goldstein RZ, Tomasi D, Alia-Klein N, Honorio Carrillo J, Maloney T, Woicik PA et al (2009). Dopaminergic response to drug words in cocaine addiction. J Neurosci 29: 6001-6006.

Gray JR, Braver TS, Raichle ME (2002). Integration of emotion and cognition in the lateral prefrontal cortex. Proc Natl Acad Sci USA 99: 4115-4120.

Greene CM, Braet W, Johnson KA, Bellgrove MA (2008). Imaging the genetics of executive function. Biol Psychol 79: 30-42.

Greicius MD, Menon V (2004). Default-mode activity during a passive sensory task: uncoupled from deactivation but impacting activation. J Cogn Neurosci 16 1484-1492.

Guevara J, Lozano P, Wickizer T, Mell L, Gephart H (2001). Utilization and cost of health care services for children with attention-deficit/hyperactivity disorder. Pediatrics 108: 71-78.

Guimaraes AR, Melcher JR, Talavage TM, Baker JR, Ledden P, Rosen BR et al (1998). Imaging subcortical auditory activity in humans. Hum Brain Mapp 6 33-41.

Gusnard DA, Akbudak E, Shulman GL, Raichle ME (2001). Medial prefrontal cortex and self-referential mental activity: relation to a default mode of brain function. Proc Natl Acad Sci USA 98: 4259-4264.

Gusnard DA, Raichle ME (2001). Searching for a baseline: functional imaging and the resting human brain. Nat Rev Neurosci 2: 685-694.

Haber SN (2003). The primate basal ganglia: parallel and integrative networks. J Chem Neuroanat 26: 317-330.

Haber SN, Brucker JL (2009). Cognitive and limbic circuits that are affected by deep brain stimulation. Front Biosci 14: 1823-1834

Hamilton LS, Levitt JG, O'Neill J, Alger JR, Luders E, Phillips OR et al (2008). Reduced white matter integrity in attention-deficit hyperactivity disorder. Neuroreport 19: 1705-1708.

Hart J, Pitcock JA, Sobkoviak R, Li J, Kraut MA (2006). Presurgical planning of neoplasms and arteriovenous malformations. In: D'Esposito (ed). Functional MRl: Applications in Clinical Neurology and Psychiatry. Taylor \& Francis, Inc.: Abingdon. pp 169-180

Hayden BY, Smith DV, Platt ML (2009). Electrophysiological correlates of defaultmode processing in macaque posterior cingulate cortex. Proc Natl Acad Sci USA 106: 5948-5953.

Hesse S, Ballaschke O, Barthel H, Sabri O (2009). Dopamine transporter imaging in adult patients with attention-deficit/hyperactivity disorder. Psychiatry Res 171: 120-128.

Hesslinger B, Tebartz van Elst L, Thiel T, Haegele K, Hennig J, Ebert D (2002). Frontoorbital volume reductions in adult patients with attention deficit hyperactivity disorder. Neurosci Lett 328: 319-321.

Hill DE, Yeo RA, Campbell RA, Hart B, Vigil J, Brooks W (2003). Magnetic resonance imaging correlates of attention-deficit/hyperactivity disorder in children. Neuropsychology 17: 496-506.

Holroyd CB (2004). Anterior cingulate cortex: selection for action, and error processing. In: Posner Ml (ed). Cognitive Neuroscience of Attention. Guilford Press: New York.

Hutchinson AD, Mathias JL, Banich MT (2008). Corpus callosum morphology in children and adolescents with attention deficit hyperactivity disorder: a metaanalytic review. Neuropsychology 22: 341-349.

Hynd GW, Hern KL, Novey ES, Eliopulos D, Marshall R, Gonzalez JJ et al (1993). Attention deficit-hyperactivity disorder and asymmetry of the caudate nucleus. J Child Neurol 8: 339-347.

Hynd GW, Semrud-Clikeman M, Lorys AR, Novey ES, Eliopulos D, Lyytinen H (1991). Corpus callosum morphology in attention deficit-hyperactivity disorder: morphometric analysis of MRI. J Learn Disabil 24: 141-146.

Ito S, Stuphorn V, Brown JW, Schall JD (2003). Performance monitoring by the anterior cingulate cortex during saccade countermanding. Science 302 120-122.

Jin Z, Zang YF, Zeng YW, Zhang L, Wang YF (2001). Striatal neuronal loss or dysfunction and choline rise in children with attention-deficit hyperactivity disorder: a 1H-magnetic resonance spectroscopy study. Neurosci Lett $\mathbf{3 1 5}$ 45-48.

Jucaite A, Fernell E, Halldin C, Forssberg H, Farde L (2005). Reduced midbrain dopamine transporter binding in male adolescents with attention-deficit/ hyperactivity disorder: association between striatal dopamine markers and motor hyperactivity. Biol Psychiatry 57: 229-238.

Kates WR, Frederikse M, Mostofsky SH, Folley BS, Cooper K, Mazur-Hopkins P et al (2002). MRI parcellation of the frontal lobe in boys with attention deficit hyperactivity disorder or Tourette syndrome. Psychiatry Res 116 : 63-81.

Kawashima R, Satoh K, Itoh H, Ono S, Furumoto S, Gotoh R et al (1996). Functional anatomy of GO/NO-GO discrimination and response selection-a PET study in man. Brain Res 728: 79-89. 
Kelly AM, Margulies DS, Castellanos FX (2007). Recent advances in structural and functional brain imaging studies of attention-deficit/hyperactivity disorder. Curr Psychiatry Rep 9: 401-407.

Kim BN, Lee JS, Cho SC, Lee DS (2001). Methylphenidate increased regional cerebral blood flow in subjects with attention deficit/hyperactivity disorder. Yonsei Med J 42: 19-29.

Kim BN, Lee JS, Shin MS, Cho SC, Lee DS (2002). Regional cerebral perfusion abnormalities in attention deficit/hyperactivity disorder. Statistical parametric mapping analysis. Eur Arch Psychiatry Clin Neurosci 252: 219-225.

Kim J, Whyte J, Wang J, Rao H, Tang KZ, Detre JA (2006). Continuous ASL perfusion $\mathrm{AMRI}$ investigation of higher cognition: quantification of tonic CBF changes during sustained attention and working memory tasks. Neuroimage $\mathbf{3 1}$ : 376-385.

Kobel M, Bechtel N, Weber P, Specht K, Klarhofer M, Scheffler K et al (2008). Effects of methylphenidate on working memory functioning in children with attention deficit/hyperactivity disorder. Eur J Paediatr Neurol. doi:10.1016/ j.ejpn.2008.10.008

Konrad K, Neufang S, Fink GR, Herpertz-Dahlmann B (2007). Long-term effects of methylphenidate on neural networks associated with executive attention in children with ADHD: results from a longitudinal functional MRI study. J Am Acad Child Adolesc Psychiatry 46: 1633-1641.

Konrad K, Neufang S, Hanisch C, Fink GR, Herpertz-Dahlmann B (2006). Dysfunctional attentional networks in children with attention deficit/hyperactivity disorder: evidence from an event-related functional magnetic resonance imaging study. Biol Psychiatry 59: 643-651.

Koten JW, Jr., Wood G, Hagoort P, Goebel R, Propping P et al (2009). Genetic contribution to variation in cognitive function: an FMRI study in twins. Science 323: $1737-1740$.

Krause KH, Dresel SH, Krause J, Kung HF, Tatsch K (2000). Increased striatal dopamine transporter in adult patients with attention deficit hyperactivity disorder: effects of methylphenidate as measured by single photon emission computed tomography. Neurosci Lett 285: 107-110.

Kronenberg G, Ende G, Alm B, Deuschle M, Heuser I, Colla M (2008). Increased NAA and reduced choline levels in the anterior cingulum following chronic methylphenidate. A spectroscopic test-retest study in adult ADHD. Eur Arch Psychiatry Clin Neurosci 258: 446-450.

Lancaster JL, Laird AR, Fox PM, Glahn DE, Fox PT (2005). Automated analysis of meta-analysis networks. Hum Brain Mapp 25: 174-184

Langleben DD, Acton PD, Austin G, Elman I, Krikorian G, Monterosso JR et al (2002). Effects of methylphenidate discontinuation on cerebral blood flow in prepubescent boys with attention deficit hyperactivity disorder. J Nucl Med 43: 1624-1629.

Laufer MW, Denhoff E (1957). Hyperkinetic behavior syndrome in children. J Pediatr 50: $463-474$

Liddle PF, Kiehl KA, Smith AM (2001). Event-related fMRI study of response inhibition. Hum Brain Mapp 12: 100-109.

Liotti M, Pliszka SR, Perez R, Kothmann D, Woldorff MG (2005). Abnormal brain activity related to performance monitoring and error detection in children with ADHD. Cortex 41: 377-388.

Lou HC, Henriksen L, Bruhn P (1984). Focal cerebral hypoperfusion in children with dysphasia and/or attention deficit disorder. Arch Neurol 41: 825-829.

Lou HC, Henriksen L, Bruhn P (1990). Focal cerebral dysfunction in developmental learning disabilities. Lancet 335: 8-11.

Lou HC, Henriksen L, Bruhn P, Borner H, Nielsen JB (1989). Striatal dysfunction in attention deficit and hyperkinetic disorder. Arch Neurol 46: 48-52.

Luu P, Flaisch T, Tucker DM (2000). Medial frontal cortex in action monitoring. J Neurosci 20: 464-469.

Lyoo IK, Noam GG, Lee CK, Lee HK, Kennedy BP, Renshaw PF (1996). The corpus callosum and lateral ventricles in children with attention-deficit hyperactivity disorder: a brain magnetic resonance imaging study. Biol Psychiatry 40: 1060-1063.

MacDonald III AW, Cohen JD, Stenger VA, Carter CS (2000). Dissociating the role of the dorsolateral prefrontal and anterior cingulate cortex in cognitive control. Science 288: 1835-1838.

MacMaster FP, Carrey N, Sparkes S, Kusumakar V (2003). Proton spectroscopy in medication-free pediatric attention-deficit/hyperactivity disorder. Biol Psychiatry 53: $184-187$

Madras BK, Xie Z, Lin Z, Jassen AJ, Panas H, Lynch L et al (2006). Modafinil occupies dopamine and norepinephrine transporters in vivo and modulates the transporters and trace amine activity in vitro. J Pharmacol Exp Ther 319: 561-569.

Makris N, Biederman J, Valera EM, Bush G, Kaiser J, Kennedy DN et al (2007). Cortical thinning of the attention and executive function networks in adults with attention-deficit/hyperactivity disorder. Cereb Cortex 17: 1364-1375. The first paper to identify specific gray matter thinning in brain regions subserving attention in adults with ADHD.

Makris N, Buka SL, Biederman J, Papadimitriou GM, Hodge SM, Valera EM et al (2008). Attention and executive systems abnormalities in adults with childhood ADHD: a DT-MRI study of connections. Cereb Cortex 18: 1210-1220.

Mataro M, Garcia-Sanchez C, Junque C, Estevez-Gonzalez A, Pujol J (1997). Magnetic resonance imaging measurement of the caudate nucleus in adolescents with attention-deficit hyperactivity disorder and its relationship with neuropsychological and behavioral measures. Arch Neurol 54: 963-968.

Matochik JA, Liebenauer LL, King AC, Szymanski HV, Cohen RM, Zametkin AJ (1994). Cerebral glucose metabolism in adults with attention deficit hyperactivity disorder after chronic stimulant treatment. Am J Psychiatry 151: 658-664.

Matochik JA, Nordahl TE, Gross M, Semple WE, King AC, Cohen RM et al (1993). Effects of acute stimulant medication on cerebral metabolism in adults with hyperactivity. Neuropsychopharmacology 8: 377-386.

Mattes JA (1980). The role of frontal lobe dysfunction in childhood hyperkinesis. Compr Psychiatry 21: 358-369.

Mayberg HS, Liotti M, Brannan SK, McGinnis S, Mahurin RK, Jerabek PA et al (1999). Reciprocal limbic-cortical function and negative mood: converging PET findings in depression and normal sadness. Am J Psychiatry 156: 675-682.

Mazoyer B, Zago L, Mellet E, Bricogne S, Etard O, Houde O et al (2001). Cortical networks for working memory and executive functions sustain the conscious resting state in man. Brain Res Bull 54: 287-298.

McClelland JL, Rumelhart DE, Group PR (1986). Parallel Distributed Processing: Explorations in the Microstructure of Cognition Volume 2: Psychological and Biological Models. MIT Press: Cambridge, MA. Essential reading for understanding PDP models.

McKiernan KA, Kaufman JN, Kucera-Thompson J, Binder JR (2003). A parametric manipulation of factors affecting task-induced deactivation in functional neuroimaging. J Cogn Neurosci 15: 394-408.

Menon V, Crottaz-Herbette S (2005). Combined EEG and fMRI studies of human brain function. Int Rev Neurobiol 66: 291-321.

Mesulam MM (1981). A cortical network for directed attention and unilateral neglect. Ann Neurol 10: 309-325.

Mesulam MM (1990). Large-scale neurocognitive networks and distributed processing for attention, language, and memory. Ann Neurol 28: 597-613.

Mesulam MM (1999). Spatial attention and neglect: parietal, frontal and cingulate contributions to the mental representation and attentional targeting of salient extrapersonal events. Philos Trans R Soc Lond B Biol Sci 354: 1325-1346.

Mick E, Faraone SV, Biederman J (2004). Age-dependent expression of attentiondeficit/hyperactivity disorder symptoms. Psychiatr Clin North Am 27: 215-224.

Monuteaux MC, Seidman LJ, Faraone SV, Makris N, Spencer T, Valera E et al (2008). A preliminary study of dopamine D4 receptor genotype and structural brain alterations in adults with ADHD. Am J Med Genet B Neuropsychiatr Genet 147B: 1436-1441

Morecraft RJ, Geula C, Mesulam MM (1993). Architecture of connectivity within a cingulo-fronto-parietal neurocognitive network for directed attention. Arch Neurol 50: 279-284.

Mostofsky SH, Reiss AL, Lockhart P, Denckla MB (1998). Evaluation of cerebellar size in attention-deficit hyperactivity disorder. J Child Neurol 13: 434-439.

Mostofsky SH, Rimrodt SL, Schafer JG, Boyce A, Goldberg MC, Pekar JJ et al (2006). Atypical motor and sensory cortex activation in attention-deficit/ hyperactivity disorder: a functional magnetic resonance imaging study of simple sequential finger tapping. Biol Psychiatry 59: 48-56.

Nigg JT, Casey BJ (2005). An integrative theory of attention-deficit/ hyperactivity disorder based on the cognitive and affective neurosciences. Dev Psychopathol 17: 785-806. A theoretical model of ADHD that emphasized and linked developmental factors with the neural substrates of cognitive, timing, emotional processes.

Norman DA, Shallice T (1986). Attention to action: willed and automatic control of behavior. In: Davidson RJ (ed). Consciousness and Self-Regulation. Plenum Press: New York. pp 515-549.

Overmeyer S, Bullmore ET, Suckling J, Simmons A, Williams SC, Santosh PJ et al (2001). Distributed grey and white matter deficits in hyperkinetic disorder: MRI evidence for anatomical abnormality in an attentional network. Psychol Med 31: 1425-1435.

Pardo JV, Fox PT, Raichle ME (1991). Localization of a human system for sustained attention by positron emission tomography. Nature 349: 61-64.

Pardo JV, Pardo PJ, Janer KW, Raichle ME (1990). The anterior cingulate cortex mediates processing selection in the Stroop attentional conflict paradigm. Proc Natl Acad Sci USA 87: 256-259

Paus T, Petrides M, Evans AC, Meyer E (1993). Role of the human anterior cingulate cortex in the control of oculomotor, manual, and speech responses: a positron emission tomography study. J Neurophysiol 70: 453-469. 
Pavuluri MN, Yang S, Kamineni K, Passarotti AM, Srinivasan G, Harral EM et al (2009). Diffusion tensor imaging study of white matter fiber tracts in pediatric bipolar disorder and attention-deficit/hyperactivity disorder. Biol Psychiatry 65: 586-593.

Perlov E, Philipsen A, Hesslinger B, Buechert M, Ahrendts J, Feige B et al (2007). Reduced cingulate glutamate/glutamine-to-creatine ratios in adult patients with attention deficit/hyperactivity disorder - a magnet resonance spectroscopy study. J Psychiatr Res 41: 934-941.

Perlov E, Philipsen A, Matthies S, Drieling T, Maier S, Bubl E et al (2008). Spectroscopic findings in attention-deficit/hyperactivity disorder: review and meta-analysis. World J Biol Psychiatry 1-11 (in press)

Picard N, Strick PL (2001). Imaging the premotor areas. Curr Opin Neurobiol 11: 663-672.

Pliszka SR (2007). Pharmacologic treatment of attention-deficit/hyperactivity disorder: efficacy, safety and mechanisms of action. Neuropsychol Rev 17: 61-72.

Pliszka SR, Glahn DC, Semrud-Clikeman M, Franklin C, Perez III R, Xiong J et al (2006). Neuroimaging of inhibitory control areas in children with attention deficit hyperactivity disorder who were treatment naive or in long-term treatment. $\mathrm{Am} \mathrm{J}$ Psychiatry 163: 1052-1060.

Pliszka SR, Liotti M, Bailey BY, Perez III R, Glahn D, Semrud-Clikeman M (2007). Electrophysiological effects of stimulant treatment on inhibitory control in children with attention-deficit/hyperactivity disorder. J Child Adolesc Psychopharmacol 17: 356-366.

Pope KS, Singer JL (1976). Regulation of the Stream of Consciousness: Toward a Theory of Ongoing Thought. Plenum Press: New York.

Posner Ml (ed) (2004). Cognitive Neuroscience of Attention. Guilford Press: New York.

Posner MI, Petersen SE (1990). The attention system of the human brain. Annu Rev Neurosci 13: 25-42. A landmark paper in cognitive neuroscience that provided a testable model of attention processing, crucial to understanding normal and disordered attention.

Posner MI, Raichle ME (1998). The neuroimaging of human brain function. Proc Natl Acad Sci USA 95: 763-764.

Posner MI, Rothbart MK (1998). Attention, self-regulation and consciousness. Philos Trans R Soc Lond B Biol Sci 353: 1915-1927.

Quay HC (ed) (1988). The Behavioral Reward and Inhibition Systems in Childhood Behavior Disorders. Vol 3. Pergamon Press: Oxford.

Raichle ME, Fiez JA, Videen TO, MacLeod AM, Pardo JV, Fox PT et al (1994). Practice-related changes in human brain functional anatomy during nonmotor learning. Cereb Cortex 4: 8-26.

Raichle ME, MacLeod AM, Snyder AZ, Powers WJ, Gusnard DA, Shulman GL (2001). A default mode of brain function. Proc Natl Acad Sci USA 98: 676-682. Seminal paper in the history of default mode network models.

Rapoport JL, Shaw P (2008). Defining the contribution of genetic risk to structural and functional anomalies in ADHD. J Am Acad Child Adolesc Psychiatry 47: 2-3.

Rauch SL, Shin LM, Phelps EA (2006). Neurocircuitry models of posttraumatic stress disorder and extinction: human neuroimaging research-past, present, and future. Biol Psychiatry 60: 376-382

Rosa-Neto P, Lou HC, Cumming P, Pryds O, Karrebaek H, Lunding J et al (2005). Methylphenidate-evoked changes in striatal dopamine correlate with inattention and impulsivity in adolescents with attention deficit hyperactivity disorder Neuroimage 25: 868-876.

Rubia K, Halari R, Smith AB, Mohammad M, Scott S, Brammer MJ (2009). Shared and disorder-specific prefrontal abnormalities in boys with pure attention-deficit/ hyperactivity disorder compared to boys with pure CD during interference inhibition and attention allocation. J Child Psychol Psychiatry 50: 669-678.

Rubia K, Overmeyer S, Taylor E, Brammer M, Williams SC, Simmons A et al (1999). Hypofrontality in attention deficit hyperactivity disorder during higher-order motor control: a study with functional MRI. Am J Psychiatry 156: 891-896.

Rumelhart DE, J.L. M, Group PR (1986). Parallel Distributed Processing: Explorations in the Microstructure of Cognition Volume 1: Foundations. MIT Press: Cambridge, MA. Essential reading for understanding PDP models.

Sagvolden T, Johansen EB, Aase H, Russell VA (2005). A dynamic developmental theory of attention-deficit/hyperactivity disorder (ADHD) predominantly hyperactive/impulsive and combined subtypes. Behav Brain Sci 28: 397-419; discussion 419-368. Exposition of an important theory of ADHD, which emerged from combined human and animal work and led to illuminating debate on various aspects of ADHD.

Satterfield JH, Dawson ME (1971). Electrodermal correlates of hyperactivity in children. Psychophysiology 8: 191-197.

Schachar R, Mota VL, Logan GD, Tannock R, Klim P (2000). Confirmation of an inhibitory control deficit in attention-deficit/hyperactivity disorder. J Abnorm Child Psychol 28: 227-235.
Schmahmann JD, Caplan D (2006). Cognition, emotion and the cerebellum. Brain 129: 290-292.

Schmahmann JD, Sherman JC (1998). The cerebellar cognitive affective syndrome. Brain 121(Part 4): 561-579.

Schmahmann JD, Weilburg JB, Sherman JC (2007). The neuropsychiatry of the cerebellum -insights from the clinic. Cerebellum 6: 254-267.

Schneider M, Retz W, Coogan A, Thome J, Rosler M (2006). Anatomical and functional brain imaging in adult attention-deficit/hyperactivity disorder (ADHD) - a neurological view. Eur Arch Psychiatry Clin Neurosci 256(Suppl 1): i32-i41.

Schott BH, Minuzzi L, Krebs RM, Elmenhorst D, Lang M, Winz OH et al (2008). Mesolimbic functional magnetic resonance imaging activations during reward anticipation correlate with reward-related ventral striatal dopamine release. J Neurosci 28: 14311-14319.

Schultz W (1998). The phasic reward signal of primate dopamine neurons. Adv Pharmacol 42: 686-690.

Schultz W, Tremblay L, Hollerman JR (2000). Reward processing in primate orbitofrontal cortex and basal ganglia. Cereb Cortex 10: 272-284.

Schultz W (2006). Behavioral theories and the neurophysiology of reward. Annu Rev Psychol 57: 87-115.

Schulz KP, Fan J, Tang CY, Newcorn JH, Buchsbaum MS, Cheung AM et al (2004). Response inhibition in adolescents diagnosed with attention deficit hyperactivity disorder during childhood: an event-related FMRI study. Am J Psychiatry 161: $1650-1657$

Schweitzer JB, Faber TL, Grafton ST, Tune LE, Hoffman JM, Kilts CD (2000). Alterations in the functional anatomy of working memory in adult attention deficit hyperactivity disorder. Am J Psychiatry 157: 278-280.

Schweitzer JB, Lee DO, Hanford RB, Tagamets MA, Hoffman JM, Grafton ST et al (2003). A positron emission tomography study of methylphenidate in adults with ADHD: alterations in resting blood flow and predicting treatment response. Neuropsychopharmacology 28: 967-973.

Secnik K, Swensen A, Lage MJ (2005). Comorbidities and costs of adult patients diagnosed with attention-deficit hyperactivity disorder. Pharmacoeconomics 23 93-102.

Seidman LJ, Doyle A, Fried R, Valera E, Crum K, Matthews L (2004a). Neuropsychological function in adults with attention-deficit/hyperactivity disorder. Psychiatr Clin North Am 27: 261-282.

Seidman LJ, Valera EM, Bush G (2004b). Brain function and structure in adults with attention-deficit/hyperactivity disorder. Psychiatr Clin North Am 27: 323-347.

Seidman LJ, Valera EM, Makris N (2005). Structural brain imaging of attentiondeficit/hyperactivity disorder. Biol Psychiatry 57: 1263-1272.

Seidman LJ, Valera EM, Makris N, Monuteaux MC, Boriel DL, Kelkar Ket al (2006). Dorsolateral prefrontal and anterior cingulate cortex volumetric abnormalities in adults with attention-deficit/hyperactivity disorder identified by magnetic resonance imaging. Biol Psychiatry 60: 1071-1080.

Semrud-Clikeman M, Pliszka SR, Lancaster J, Liotti M (2006). Volumetric MRI differences in treatment-naive vs chronically treated children with ADHD. Neurology 67: 1023-1027.

Semrud-Clikeman M, Steingard RJ, Filipek P, Biederman J, Bekken K, Renshaw PF (2000). Using MRI to examine brain-behavior relationships in males with attention deficit disorder with hyperactivity. J Am Acad Child Adolesc Psychiatry 39: $477-484$

Sergeant J (2000). The cognitive-energetic model: an empirical approach to attention-deficit hyperactivity disorder. Neurosci Biobehav Rev 24: 7-12. A key reference that advocated a multi-level network model to help explain ADHD and attempted to link this to human and animal work.

Sergeant JA (2005). Modeling attention-deficit/hyperactivity disorder: a critical appraisal of the cognitive-energetic model. Biol Psychiatry 57: 1248-1255.

Sergeant JA, Geurts H, Oosterlaan J (2002). How specific is a deficit of executive functioning for attention-deficit/hyperactivity disorder? Behav Brain Res 130: 3-28.

Shafritz KM, Marchione KE, Gore JC, Shaywitz SE, Shaywitz BA (2004). The effects of methylphenidate on neural systems of attention in attention deficit hyperactivity disorder. Am J Psychiatry 161: 1990-1997.

Shaw P, Eckstrand K, Sharp W, Blumenthal J, Lerch JP, Greenstein D et al (2007a). Attention-deficit/hyperactivity disorder is characterized by a delay in cortical maturation. Proc Natl Acad Sci USA 104: 19649-19654. Developmental lag in brain structures revealed by structural imaging

Shaw P, Gornick M, Lerch J, Addington A, Seal J, Greenstein D et al (2007b). Polymorphisms of the dopamine D4 receptor, clinical outcome, and cortical structure in attention-deficit/hyperactivity disorder. Arch Gen Psychiatry 64: 921-931

Shaw P, Lerch J, Greenstein D, Sharp W, Clasen L, Evans A et al (2006). Longitudinal mapping of cortical thickness and clinical outcome in children and adolescents with attention-deficit/hyperactivity disorder. Arch Gen Psychiatry 63 
540-549. The first paper to identify specific gray matter thinning in brain regions subserving attention in youth with ADHD.

Shaywitz BA, Klopper JH, Gordon JW (1978). Methylphenidate in 6-hydroxydopamine-treated developing rat pups. Effects on activity and maze performance. Arch Neurol 35: 463-469.

Shulman GL, Astafiev SV, Franke D, Pope DL, Snyder AZ, McAvoy MP et al (2009). Interaction of stimulus-driven reorienting and expectation in ventral and dorsal frontoparietal and basal ganglia-cortical networks. J Neurosci 29: 4392-4407.

Shulman GL, Fiez JA, Corbetta M, Buckner RL, Miezin FM, Raichle ME et al (1997). Common blood flow changes across visual tasks: II. Decreases in cerebral cortex. J Cogn Neurosci 9: 648-663.

Silk T, Vance A, Rinehart N, Egan G, O'Boyle M, Bradshaw JL et al (2005). Frontoparietal activation in attention-deficit hyperactivity disorder, combined type: functional magnetic resonance imaging study. $\mathrm{Br} J$ Psychiatry 187: 282-283.

Silk TJ, Vance A, Rinehart N, Bradshaw JL, Cunnington R (2008). White-matter abnormalities in attention deficit hyperactivity disorder: a diffusion tensor imaging study. Hum Brain Mapp 30: 2757-2765.

Simpson Jr JR, Drevets WC, Snyder AZ, Gusnard DA, Raichle ME (2001a). Emotion-induced changes in human medial prefrontal cortex: II. During anticipatory anxiety. Proc Natl Acad Sci USA 98: 688-693.

Simpson Jr JR, Snyder AZ, Gusnard DA, Raichle ME (2001b). Emotion-induced changes in human medial prefrontal cortex: I. During cognitive task performance. Proc Natl Acad Sci USA 98: 683-687.

Simpson JR, Ongur D, Akbudak E, Conturo TE, Ollinger JM, Snyder AZ et al (2000). The emotional modulation of cognitive processing: an fMRl study. J Cogn Neurosci 12(Suppl 2): 157-170.

Smith AB, Taylor E, Brammer M, Halari R, Rubia K (2008). Reduced activation in right lateral prefrontal cortex and anterior cingulate gyrus in medication-naive adolescents with attention deficit hyperactivity disorder during time discrimination. J Child Psychol Psychiatry 49: 977-985.

Smith AB, Taylor E, Brammer M, Toone B, Rubia K (2006). Task-specific hypoactivation in prefrontal and temporoparietal brain regions during motor inhibition and task switching in medication-naive children and adolescents with attention deficit hyperactivity disorder. Am J Psychiatry 163: 1044-1051.

Solanto MV (2002). Dopamine dysfunction in AD/HD: integrating clinical and basic neuroscience research. Behav Brain Res 130: 65-71.

Solomon P, E. KP, Leiderman PH, Mendelson JH, Trumbull R, Wexler D (1961). Sensory Deprivation. Harvard University Press: Cambridge, MA

Sonuga-Barke EJ (2003). The dual pathway model of AD/HD: an elaboration of neuro-developmental characteristics. Neurosci Biobehav Rev 27: 593-604. One of the most influential current theories of ADHD pathophysiology]

Sonuga-Barke EJ (2005). Causal models of attention-deficit/hyperactivity disorder: from common simple deficits to multiple developmental pathways. Biol Psychiatry 57: 1231-1238.

Sonuga-Barke EJ, Castellanos FX (2007). Spontaneous attentional fluctuations in impaired states and pathological conditions: a neurobiological hypothesis. Neurosci Biobehav Rev 31: 977-986.

Sonuga-Barke EJ, Sergeant J (2005). The neuroscience of ADHD: multidisciplinary perspectives on a complex developmental disorder. Dev Sci 8: 103-104.

Sonuga-Barke EJ, Sergeant JA, Nigg J, Willcutt E (2008). Executive dysfunction and delay aversion in attention deficit hyperactivity disorder: nosologic and diagnostic implications. Child Adolesc Psychiatr Clin N Am 17: 367-384, ix

Spencer T, Biederman J, Ciccone P, Madras B, Dougherty D, Bonab A et al (2006). A PET study examining pharmacokinetics, detection and likeability, and dopamine transporter receptor occupancy of short and long-acting orally administered formulations of methylphenidate in adults. Am J Psychiatry 163: 387-395. Important display of how PET measures correlate with methylphenidate dosing

Spencer TJ, Biederman J, Madras BK, Faraone SV, Dougherty DD, Bonab AA et al (2005). In vivo neuroreceptor imaging in attention-deficit/hyperactivity disorder: a focus on the dopamine transporter. Biol Psychiatry 57: 1293-1300.

Still GF (1902). Some abnormal psychical conditions in children. Lancet 1: 10081012, 1077-1082, 1163-1168.

Stoodley CJ, Schmahmann JD (2009). Functional topography in the human cerebellum: a meta-analysis of neuroimaging studies. Neuroimage 44: 489-501.

Sun L, Jin Z, Zang YF, Zeng YW, Liu G, Li Y et al (2005). Differences between attention-deficit disorder with and without hyperactivity: a $1 \mathrm{H}$-magnetic resonance spectroscopy study. Brain Dev 27: 340-344.

Swanson J, Castellanos FX, Murias M, LaHoste G, Kennedy J (1998). Cognitive neuroscience of attention deficit hyperactivity disorder and hyperkinetic disorder. Curr Opin Neurobio/ 8: 263-271.

Swanson JM, Kinsbourne M, Nigg J, Lanphear B, Stefanatos GA, Volkow N et al (2007). Etiologic subtypes of attention-deficit/hyperactivity disorder: brain imaging, molecular genetic and environmental factors and the dopamine hypothesis. Neuropsychol Rev 17: 39-59.

Tamm L, Menon V, Reiss AL (2006). Parietal attentional system aberrations during target detection in adolescents with attention deficit hyperactivity disorder: eventrelated fMRI evidence. Am J Psychiatry 163: 1033-1043.

Tamm L, Menon V, Ringel J, Reiss AL (2004). Event-related FMRI evidence of frontotemporal involvement in aberrant response inhibition and task switching in attention-deficit/hyperactivity disorder. J Am Acad Child Adolesc Psychiatry 43: 1430-1440.

Tannock R (1998). Attention deficit hyperactivity disorder: advances in cognitive, neurobiological, and genetic research. J Child Psychol Psychiatry 39: 65-99.

Teasdale JD, Dritschel BH, Taylor MJ, Proctor L, Lloyd CA, Nimmo-Smith I et al (1995). Stimulus-independent thought depends on central executive resources. Mem Cognit 23: 551-559.

Teicher MH, Anderson CM, Polcari A, Glod CA, Maas LC, Renshaw PF (2000). Functional deficits in basal ganglia of children with attention-deficit/hyperactivity disorder shown with functional magnetic resonance imaging relaxometry. Nat Med 6: 470-473.

Tian L, Jiang T, Liang M, Zang Y, He Y, Sui M et al (2008). Enhanced resting-state brain activities in ADHD patients: a fMRI study. Brain Dev 30: 342-348.

Tian L, Jiang T, Wang Y, Zang Y, He Y, Liang M et al (2006). Altered resting-state functional connectivity patterns of anterior cingulate cortex in adolescents with attention deficit hyperactivity disorder. Neurosci Lett 400: 39-43.

Turken AU, Swick D (1999). Response selection in the human anterior cingulate cortex. Nat Neurosci 2: 920-924.

Uddin LQ, Kelly AM, Biswal BB, Margulies DS, Shehzad Z, Shaw D et al (2008). Network homogeneity reveals decreased integrity of default-mode network in ADHD. J Neurosci Methods 169: 249-254.

Ullsperger M, von Cramon DY (2003). Error monitoring using external feedback: specific roles of the habenular complex, the reward system, and the cingulate motor area revealed by functional magnetic resonance imaging. J Neurosci 23: 4308-4314.

Vaidya CJ, Austin G, Kirkorian G, Ridlehuber HW, Desmond JE, Glover GH et al (1998). Selective effects of methylphenidate in attention deficit hyperactivity disorder: a functional magnetic resonance study. Proc Natl Acad Sci USA 95: 14494-14499. Pioneering fMRI study of methylphenidate in children with ADHD

Vaidya CJ, Bunge SA, Dudukovic NM, Zalecki CA, Elliott GR, Gabrieli JD (2005). Altered neural substrates of cognitive control in childhood ADHD: evidence from functional magnetic resonance imaging. Am J Psychiatry 162: 1605-1613.

Vaidya CJ, Stollstorff M (2008). Cognitive neuroscience of attention deficit hyperactivity disorder: current status and working hypotheses. Dev Disabil Res Rev 14: 261-267.

Valera EM, Faraone SV, Biederman J, Poldrack RA, Seidman LJ (2005). Functional neuroanatomy of working memory in adults with attention-deficit/hyperactivity disorder. Biol Psychiatry 57: 439-447.

Valera EM, Faraone SV, Murray KE, Seidman LJ (2007). Meta-analysis of structural imaging findings in attention-deficit/hyperactivity disorder. Biol Psychiatry 61: 1361-1369.

Vance A, Silk TJ, Casey M, Rinehart NJ, Bradshaw JL, Bellgrove MA et al (2007). Right parietal dysfunction in children with attention deficit hyperactivity disorder, combined type: a functional MRI study. Mol Psychiatry 12: 826-832, 793.

Vogt BA (2005). Pain and emotion interactions in subregions of the cingulate gyrus. Nat Rev Neurosci 6: 533-544.

Vogt BA, Finch DM, Olson CR (1992). Functional heterogeneity in cingulate cortex: the anterior executive and posterior evaluative regions. Cereb Cortex 2: 435-443.

Vogt BA, Gabriel M (1993). Neurobiology of Cingulate Cortex and Limbic Thalamus: A Comprehensive Handbook. Birkhäuser: Boston.

Volkow ND, Fowler JS, Wang G, Ding Y, Gatley SJ (2002). Mechanism of action of methylphenidate: insights from PET imaging studies. J Atten Disord 6(Suppl 1): S31-S43.

Volkow ND, Wang G, Fowler JS, Logan J, Gerasimov M, Maynard L et al (2001). Therapeutic doses of oral methylphenidate significantly increase extracellular dopamine in the human brain. $J$ Neurosci 21: RC121.

Volkow ND, Wang GJ, Fowler JS, Ding YS (2005). Imaging the effects of methylphenidate on brain dopamine: new model on its therapeutic actions for attention-deficit/hyperactivity disorder. Biol Psychiatry 57: 1410-1415. Good synthesis of neuroimaging data on mechanisms of methylphenidate.

Volkow ND, Wang GJ, Fowler JS, Gatley SJ, Logan J, Ding YS et al (1998). Dopamine transporter occupancies in the human brain induced by therapeutic doses of oral methylphenidate. Am J Psychiatry 155: 1325-1331.

Volkow ND, Wang GJ, Newcorn J, Fowler JS, Telang F, Solanto MV et al (2007). Brain dopamine transporter levels in treatment and drug naive adults with ADHD. Neuroimage 34: 1182-1190. 
Vos T, Haby MM, Magnus A, Mihalopoulos C, Andrews G, Carter R (2005) Assessing cost-effectiveness in mental health: helping policy-makers prioritize and plan health services. Aust NZ J Psychiatry 39: 701-712.

Wager TD, Davidson ML, Hughes BL, Lindquist MA, Ochsner KN (2008). Prefrontalsubcortical pathways mediating successful emotion regulation. Neuron 59 1037-1050.

Wang Z, Wang J, Connick TJ, Wetmore GS, Detre JA (2005). Continuous ASL (CASL) perfusion MRI with an array coil and parallel imaging at 3T. Magn Reson Med 54: 732-737.

Weissman DH, Roberts KC, Visscher KM, Woldorff MG (2006). The neural bases of momentary lapses in attention. Nat Neurosci 9: 971-978.

Werry JS (ed) (1992). History, Terminology, and Manifestations at Different Ages. W.B. Saunders: Philadelphia.

Whalen PJ, Bush G, McNally RJ, Wilhelm S, Mclnerney SC, Jenike MA et al (1998). The emotional counting Stroop paradigm: a functional magnetic resonance imaging probe of the anterior cingulate affective division. Biol Psychiatry 44 1219-1228.

Williams ZM, Bush G, Rauch SL, Cosgrove GR, Eskandar EN (2004). Human anterior cingulate neurons and the integration of monetary reward with motor responses. Nat Neurosci 7: 1370-1375.

Wolosin SM, Richardson ME, Hennessey JG, Denckla MB, Mostofsky SH (2009). Abnormal cerebral cortex structure in children with ADHD. Hum Brain Mapp 30: $175-184$
Yeo RA, Hill DE, Campbell RA, Vigil J, Petropoulos H, Hart B et al (2003). Proton magnetic resonance spectroscopy investigation of the right frontal lobe in children with attention-deficit/hyperactivity disorder. J Am Acad Child Adolesc Psychiatry 42: 303-310.

Zametkin AJ, Liotta W (1998). The neurobiology of attention-deficit/hyperactivity disorder. J Clin Psychiatry 59(Suppl 7): 17-23.

Zametkin AJ, Nordahl TE, Gross M, King AC, Semple WE, Rumsey J et al (1990). Cerebral glucose metabolism in adults with hyperactivity of childhood onset. N Engl J Med 323: 1361-1366. Seminal large-scale PET study of ADHD adults that showed global and regional hypometabolism in ADHD adults.

Zang YF, Jin Z, Weng XC, Zhang L, Zeng YW, Yang L et al (2005). Functional MRI in attention-deficit hyperactivity disorder: evidence for hypofrontality. Brain Dev 27: 544-550

Zang YF, Yong H, Chao-Zhe Z, Qing-Jiu C, Man-Qiu S, Meng L et al (2006). Altered baseline brain activity in children with $A D H D$ revealed by resting-state functional MRI. Brain Dev 29: 83-91.

Zhu CZ, Zang YF, Cao QJ, Yan CG, He Y, Jiang TZ et al (2008). Fisher discriminative analysis of resting-state brain function for attention-deficit/hyperactivity disorder. Neuroimage 40: 110-120.

Zhu CZ, Zang YF, Liang M, Tian LX, He Y, Li XB et al (2005). Discriminative analysis of brain function at resting-state for attention-deficit/hyperactivity disorder. Med Image Comput Comput Assist Interv Int Conf Med Image Comput Comput Assist Interv 8: 468-475. 